\title{
Modeling of Heat Transfer Attenuation by Ablative Gases During the Stardust Reentry
}

\author{
Alexandre Martin* \\ University of Kentucky, Lexington, Kentucky 40506 \\ and \\ Iain D. BoydI \\ University of Michigan, Ann Arbor, Michigan 48109 \\ DOI: $\underline{10.2514 / 1 . T 4202}$
}

\begin{abstract}
Modern space vehicles designed for planetary exploration use ablative materials to protect the payload against the high heating environment experienced during reentry. To properly model and predict the aerothermal environment of the vehicle, it is imperative to account for the gases produced by ablation processes. The present study aims to examine the effects of the blowing of ablation gas in the outer flow field. Using six points on the Stardust entry trajectory at the beginning of the continuum regime, from 81 to $69 \mathrm{~km}$, the various components of the heat flux are compared to air-only solutions. Although an additional component of the heat flux is introduced by mass diffusion, this additional term is mainly balanced by the fact that the translational-rotational component of the heat flux, the main contributor, is greatly reduced. Although a displacement of the shock is observed, it is believed that the most prominent effects are caused by a modification of the chemical composition of the boundary layer, which reduces the gas-phase thermal conductivity.
\end{abstract}

\section{Nomenclature}

$B^{\prime}=$ nondimensional ablation rate

$C=$ vector of source terms

$D=$ mass diffusion coefficient, $\mathrm{m}^{2} / \mathrm{s}$

$E=$ energy, $\mathrm{J} / \mathrm{m}^{3}$

$e \quad=$ energy, $\mathrm{J} / \mathrm{kg}$

$\boldsymbol{F} \quad=$ inviscid flux matrix

$\boldsymbol{F}_{d} \quad=$ diffusive flux matrix

$h=$ species enthalpy vector, $\mathrm{J} / \mathrm{kg}$

$\boldsymbol{I}=$ identity matrix

$\boldsymbol{J}=$ directional species diffusion, $\mathrm{kg} /\left(\mathrm{m}^{2} \cdot \mathrm{s}\right)$

$K n=$ Knudsen number

$\boldsymbol{k}=$ thermal conductivity, $\mathrm{W} /(\mathrm{m} \cdot \mathrm{K})$

$\dot{m}^{\prime \prime}=$ mass flow rate, $\mathrm{kg} /\left(\mathrm{m}^{2} \cdot \mathrm{s}\right)$

$p=$ pressure, $\mathrm{Pa}$

$\boldsymbol{Q}=$ vector of conserved variables

$q=$ heat flux, $\mathrm{W} / \mathrm{m}^{2}$

$T=$ temperature, $\mathrm{K}$

$U, v=$ velocity, $\mathrm{m} / \mathrm{s}$

$\dot{\boldsymbol{w}}=$ mass source term, $\mathrm{kg} /\left(\mathrm{m}^{3} \cdot \mathrm{s}\right)$

$\dot{w}_{v}=$ vibrational energy relaxation source term, $\mathrm{J} /\left(\mathrm{m}^{3} \cdot \mathrm{s}\right)$

$Y=$ mass fraction, $\mathrm{kg} / \mathrm{kg}$

$\eta \quad=$ distance normal to the wall, $\mathrm{m}$

$\rho \quad=$ mass density, $\mathrm{kg} / \mathrm{m}^{3}$

$\tau=$ viscous tensor, $\mathrm{Pa}$

Subscripts

$c \quad=$ char

$g \quad=$ gas blown

nc $\quad=$ next to the wall

Presented as Paper 2011-0143 at the AIAA Aerospace Sciences Meeting and Exhibit, Orlando, FL, 4-7 January 2011; received 1 June 2013; revision received 15 September 2014; accepted for publication 24 January 2015; published online 8 April 2015. Copyright $\odot 2014$ by Alexandre Martin and Iain D. Boyd. Published by the American Institute of Aeronautics and Astronautics, Inc., with permission. Copies of this paper may be made for personal or internal use, on condition that the copier pay the $\$ 10.00$ per-copy fee to the Copyright Clearance Center, Inc., 222 Rosewood Drive, Danvers, MA 01923; include the code 1533-6808/15 and $\$ 10.00$ in correspondence with the CCC

*Assistant Professor, Department of Mechanical Engineering, 261 Ralph G. Anderson Building. Associate Fellow AIAA.

JJames E. Knott Professor of Engineering, Department of Aerospace Engineering, 3000 Francois-Xavier Bagnoud Building. Fellow AIAA.

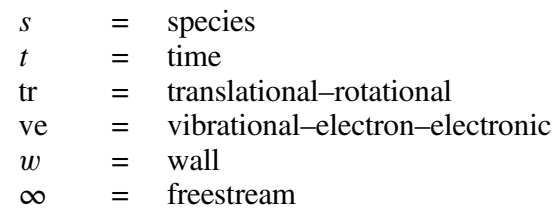

\section{Introduction}

$\mathbf{O}$ NE of the most important components of a reentry vehicle is its thermal protection system (TPS). Depending on the reentry trajectory and atmospheric conditions, two types of materials may be used for TPS design: ablative materials, such as the ones used on the Apollo missions, and non-ablative materials, such as the ceramic tiles used on the Space Shuttle. For most planetary exploration missions, a multi-component ablative material is most frequently used. In this type of material, an inner resin is first chemically and thermally decomposed before the surface begins to react. This type of ablator, called charring or pyrolysing ablator, offers multiple advantages, like generating a relatively cold pyrolysis gas that travels through the char layer or expelling that gas at the surface, which modifies the transport properties, thus the heat flux transmitted to the vehicle.

To properly model the heating rates at the surface of the vehicle, the ablating boundary condition must take into account many phenomena: surface recession, wall temperature, blowing rates, gas composition, surface chemistry, etc. However, to account for the effects of the pyrolysis gas on the vehicle, the chemistry model of the flow field must include the reactions associated with the presence of this gas. Because ablation coupling is becoming an increasingly important research topic [1-7], the development of an accurate, yet usable, chemistry model is of great importance. Models have been proposed in the past [8-10], but important reactions were not included, and some of the reaction rates were inappropriate or simply outdated.

Recently, a more complete model was proposed [11,12], which includes an extensive set of kinetic rates taken from the combustion community. The model was reduced using zero-dimensional sensitivity analysis over a parameter space relevant to the reentry conditions that such a material would be exposed to. It was established that such a model was necessary to study carbon-phenolic TPS through a review of past models, which gave a wide range of results, especially when radiative heat transfer calculations were performed [13]. The reduced model was later integrated into the hypersonic computational fluid dynamics (CFD) code LeMANS. As a test case, results were obtained at various trajectory points of the Stardust reentry vehicle, and the importance of accounting for ablation in flow field 


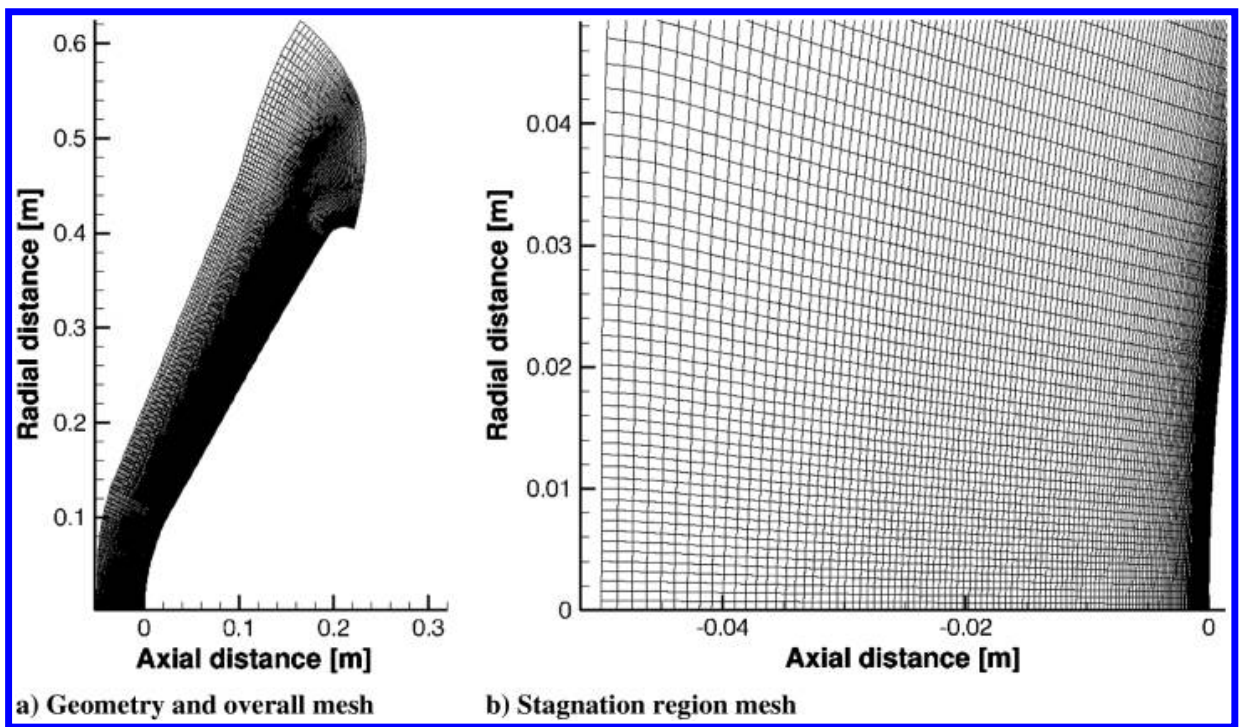

Fig. 1 Geometry and mesh of the Stardust reentry capsule, used for the chemistry model comparison. The mesh has 165 points along the wall and 238 points along the axis.

chemistry was highlighted $[\underline{12}, \underline{14}]$. A later paper [15] focused on the $71 \mathrm{~km}$ trajectory point, for which spectrally resolved radiative emission measurements were obtained. The experimental data were compared to the computed results, which were processed using the NEQAIR (version 7) radiation code [16]. The agreement was surprisingly good, considering the high level of assumptions and uncertainties of both the experimental data and the computations.

The current paper further analyzes the Stardust trajectory between 81 and $69 \mathrm{~km}$. Six trajectory points are analyzed, and an attempt is made to identify the key aspects of the heat flux reduction caused by pyrolysis gas injection.

Finally, for validation purposes, a comparison is made with the experimental data obtained with the echelle spectrometer at altitudes of 71 and $81 \mathrm{~km}$. A good agreement is noted at $71 \mathrm{~km}$, as previously published [15], and an even better one is obtained at $81 \mathrm{~km}$. These results show the validity of the chemistry model used in the CFD code and demonstrate that the assumptions made for calculating blowing rates and pyrolysis gas composition are reasonable.

The results presented here are unique as they provide a detailed analysis of how the ablation species are transported in the flow field and subsequently affect the surface heat fluxes. Moreover, the results use actual trajectory data to perform the calculation and are compared to experimental measurements.

\section{Chemistry Model}

The chemistry model used in this analysis has been developed and optimized for vehicles equipped with ablative heat shields composed of Carbon-Phenolic that reenter in a $\mathrm{N}_{2}-\mathrm{O}_{2}$ atmosphere $[11,12,14]$. The species and reaction mechanisms used in the model were carefully selected using a material response analysis. The corresponding kinetic chemistry rates were taken from the GRI-Mech model and then reduced using a sensitivity analysis [11-14]. The reduced model contains 38 species and 158 reaction rates. The selected species can be grouped into three categories, as follows.

1) The air species:

$$
\mathrm{N}_{2}, \mathrm{O}_{2}, \mathrm{NO}, \mathrm{N}, \mathrm{O}, \mathrm{N}_{2}^{+}, \mathrm{O}_{2}^{+}, \mathrm{NO}^{+}, \mathrm{N}^{+}, \mathrm{O}^{+}, \mathrm{e}
$$

2) The boundary-layer and surface species:
3) And the reacting species:

$$
\begin{aligned}
& \mathrm{H}, \mathrm{NH}, \mathrm{HO}_{2}, \mathrm{H}_{2} \mathrm{O}_{2}, \mathrm{HCO}, \mathrm{C}, \mathrm{C}_{2}, \mathrm{CH}, \mathrm{CH}_{2}, \mathrm{CH}_{3}, \mathrm{NCO}, \mathrm{HNO} \\
& \mathrm{CO}^{+}, \mathrm{CN}^{+}, \mathrm{C}^{+}, \mathrm{H}^{+}
\end{aligned}
$$

The reaction mechanisms and forward kinetics rates are listed in Refs. [11,12]. Gibb's free energy is used to calculate the equilibrium constants needed for the backward reaction rates. The model has been validated with multiple zero-dimensional simulations performed using the CHEMKIN [17] package and compared to available experimental data that are representative of an ablative boundary layer during hypersonic reentry [13].

\section{LeMANS: Unstructured Three-Dimensional Navier-Stokes Solver for Hypersonic Non-Equilibrium Aerothermodynamics}

The hypersonic aerothermodynamic CFD code used in the present analysis is LeMANS, a finite-volume Navier-Stokes solver [18]. The code assumes that the rotational and translational energy modes of all species can be described by a single temperature $T$ and that the vibrational energy mode and electronic energy mode of all species, as well as the free electron kinetic energy, can be described by another single temperature $T_{\mathrm{ve}}$. The following equations are therefore solved:

$$
\frac{\partial \boldsymbol{Q}}{\partial t}+\nabla \cdot\left(\boldsymbol{F}-\boldsymbol{F}_{d}\right)=\boldsymbol{C}
$$

where

$$
\boldsymbol{Q}=\left(\begin{array}{c}
\rho \boldsymbol{Y}^{T} \\
\rho \boldsymbol{u}^{T} \\
E \\
E_{\mathrm{ve}}
\end{array}\right) \text { and } \boldsymbol{C}=\left(\begin{array}{c}
\dot{\boldsymbol{w}}^{T} \\
0^{T} \\
0 \\
\dot{w}_{v}
\end{array}\right)
$$

are the vector of conserved variables and the vector of source terms, respectively. In these equations, $\boldsymbol{Y}=\left(Y_{1}, \ldots, Y_{\mathrm{ns}}\right)$ is the species densities vector, $\boldsymbol{u}$ is the bulk velocity components, and $E$ and $E_{\mathrm{ve}}$ are the total and the vibrational-electron-electronic excitation energy per unit volume of mixture, respectively.

The inviscid and diffusive flux matrices are given by

$$
\boldsymbol{F}=\left(\begin{array}{c}
\rho \boldsymbol{Y}^{T} \boldsymbol{u} \\
\rho \boldsymbol{u}^{T} \boldsymbol{u}+\boldsymbol{I} p \\
(E+p) \boldsymbol{u} \\
E_{\mathrm{ve}} \boldsymbol{u}
\end{array}\right) \quad \text { and } \quad \boldsymbol{F}_{d}=\left(\begin{array}{c}
-\boldsymbol{J} \\
\tau \\
\boldsymbol{u} \tau-\left(\boldsymbol{q}_{\mathrm{tr}}+\boldsymbol{q}_{\mathrm{ve}}\right)-\left(\boldsymbol{h}^{T} \boldsymbol{J}\right) \\
-\boldsymbol{q}_{\mathrm{ve}}-\left(\boldsymbol{e}_{\mathrm{ve}}^{T} \boldsymbol{J}\right)
\end{array}\right)
$$


Table 1 Freestream conditions used for the Stardust trajectory

\begin{tabular}{lccccccc}
\hline \hline Altitude, $\mathrm{km}$ & Time, $\mathrm{s}$ & $U_{\infty}, \mathrm{km} / \mathrm{s}$ & $T_{\infty}, \mathrm{K}$ & $\rho_{\infty}, \mathrm{kg} / \mathrm{m}^{3}$ & $Y_{\mathrm{N}}$ & $Y_{\mathrm{O}}$ & $K n$ \\
\hline 81.0 & 34 & 12.4 & 218. & $1.27 \times 10^{-4}$ & 0.763 & 0.237 & 0.00645 \\
78.5 & 36 & 12.3 & 218. & $1.87 \times 10^{-4}$ & 0.763 & 0.237 & 0.00432 \\
76.0 & 38 & 12.3 & 219. & $2.72 \times 10^{-4}$ & 0.763 & 0.237 & 0.00292 \\
73.5 & 40 & 12.2 & 220. & $3.92 \times 10^{-4}$ & 0.763 & 0.237 & 0.00203 \\
71.2 & 42 & 12.1 & 222. & $5.55 \times 10^{-4}$ & 0.763 & 0.237 & 0.00145 \\
68.9 & 44 & 11.9 & 224. & $7.72 \times 10^{-4}$ & 0.763 & 0.237 & 0.00105 \\
\hline \hline
\end{tabular}

Table 2 Wall conditions at the stagnation point for the Stardust trajectory

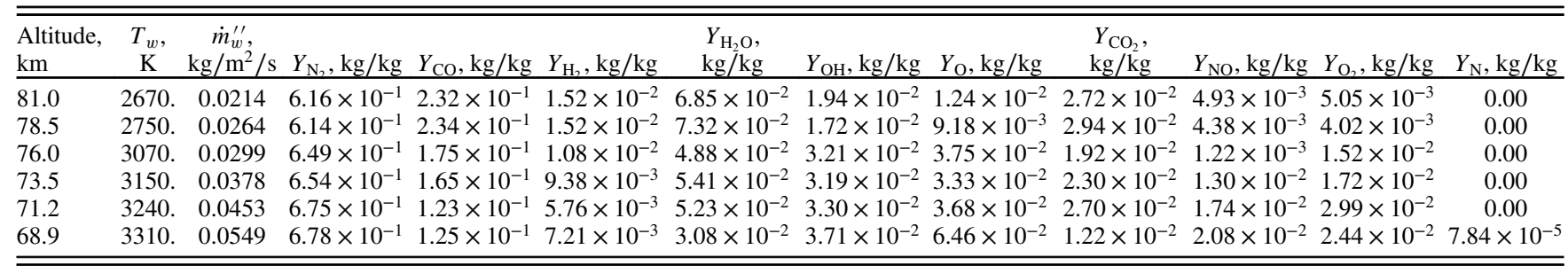

where $p$ is the pressure, $\tau$ is the viscous tensor, and $\boldsymbol{q}_{\mathrm{tr}}$ and $\boldsymbol{q}_{\mathrm{ve}}$ are the directional translational-rotational and vibrational-electron-electronic excitation heat flux vectors, respectively, calculated using Fourier's law of conduction:

$$
q_{i}=k_{i} \nabla T_{i}
$$

where $k_{i}$ is the thermal conductivity, and index $i$ represents the various energy modes (in the present case, either tr or ve). Moreover, $\boldsymbol{h}$ is the species enthalpy vector, and $\boldsymbol{J}$ is the directional species diffusion flux tensor. The details of these equations and models are found in [19].

The viscous stresses in $\tau$ are modeled assuming a Newtonian fluid using Stokes's hypothesis, and the species mass diffusion fluxes are modeled using a modified version of Fick's law, which forces the sum of all diffusion velocity to be zero.

The species transport properties are calculated from LennardJones potentials, using CHEMKIN [17], to produce individual species temperature dependent viscosity curve fits (Blotter's model [20]). Mixture transport properties are calculated using Wilke's semiempirical mixing rule [21], and species thermal conductivities are determined using Eucken's relation [22]. According to the constant Lewis number assumption, the diffusion coefficient of each species is assumed to be equal. Heat fluxes are modeled according to Fourier's law for all temperatures. Finally, the source terms of the species conservation equations are modeled using a standard finite-rate chemistry model for reacting air in conjunction with Park's twotemperature model [23] to account for thermal non-equilibrium effects on the reaction rates.

The code has the capability to handle meshes containing any mix of hexahedra, tetrahedra, prisms, and pyramids in three dimensions or triangles and quadrilaterals in two dimensions. Numerical fluxes between the cells are discretized using a modified Steger-Warming flux vector splitting scheme, which has low dissipation and is appropriate to calculate boundary layers. A point or line implicit method is used to perform the time integration. The code has been extensively validated against experimental data $[19,24-33]$ and has also been compared to other similar codes such as $\overline{\mathrm{NA}} \overline{\mathrm{SA}}$ Ames's DPLR [34] and NASA Langley's LAURA [35].

To account for the coupling between the flow field and the material response, the effects of ablation are added to the CFD code; therefore, a modification to the surface boundary condition is necessary. The physical values at the wall are obtained by solving the surface momentum balance equation:

$$
p_{\mathrm{nc}}+\rho_{\mathrm{nc}} v_{\mathrm{nc}}^{2}=p_{w}\left(\rho_{w}, T_{w}\right)+\rho_{w} v_{w}^{2}
$$

It is to be noted that the diffusive fluxes are neglected in this relation. Using perfect gas relation, the density, pressure, and velocity at the wall can be calculated:

$$
\rho_{w}=\frac{p_{\eta}+\sqrt{\left.p_{\eta}^{2}-4 R T_{w} \dot{m}_{w}^{\prime \prime 2}\right)}}{2 R T_{w}}
$$

$$
v_{w}=\frac{2 R T_{w} \dot{m}_{w}^{\prime \prime}}{p_{\eta}+\sqrt{\left.p_{\eta}^{2}-4 R T_{w} \dot{m}_{w}^{\prime \prime 2}\right)}}
$$

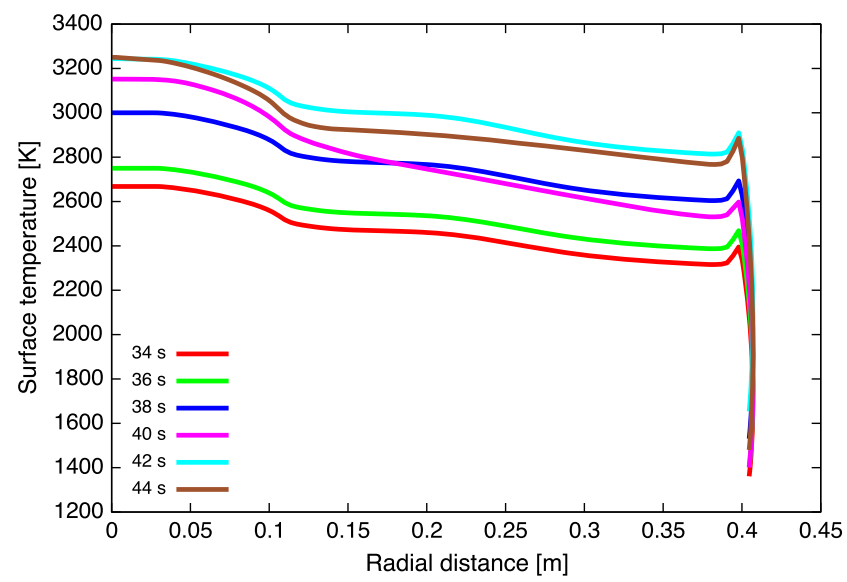

a) Surface temperature

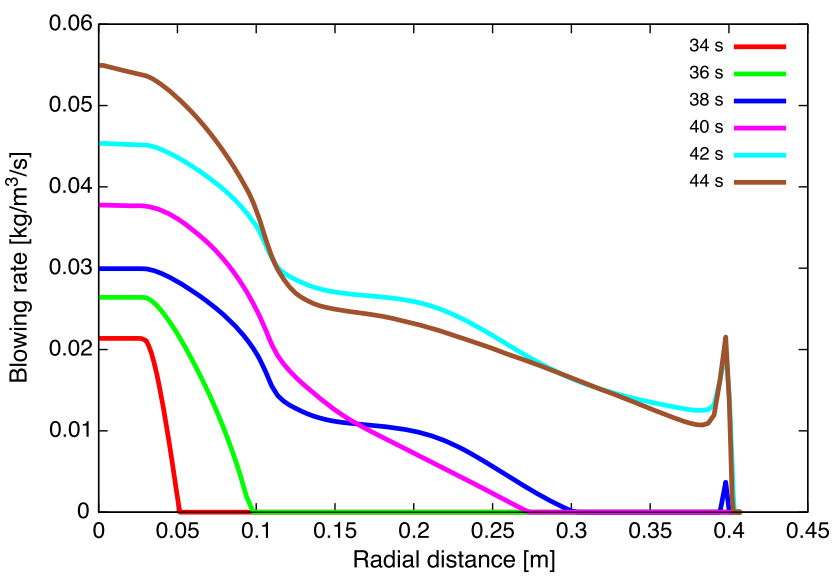

b) Surface blowing rate

Fig. 2 Imposed surface temperature and blowing rates for the echelle part of the trajectory of Stardust. 


$$
p_{w}=\frac{p_{\eta}+\sqrt{\left.p_{\eta}^{2}-4 R T_{w} \dot{m}_{w}^{\prime \prime 2}\right)}}{2}
$$

The mass fractions of the species leaving the wall $\left(Y_{w s}\right)$ are calculated using a surface mass balance equation:

$$
\rho_{w} D_{w s} \frac{\partial Y_{w s}}{\partial \eta}+\dot{m}_{w}^{\prime \prime} Y_{w s}=\dot{m}_{w}^{\prime \prime} Y_{g s}
$$

The left side of the equation represents the diffusive and convective flux approaching the wall, from the flow field domain, and the right

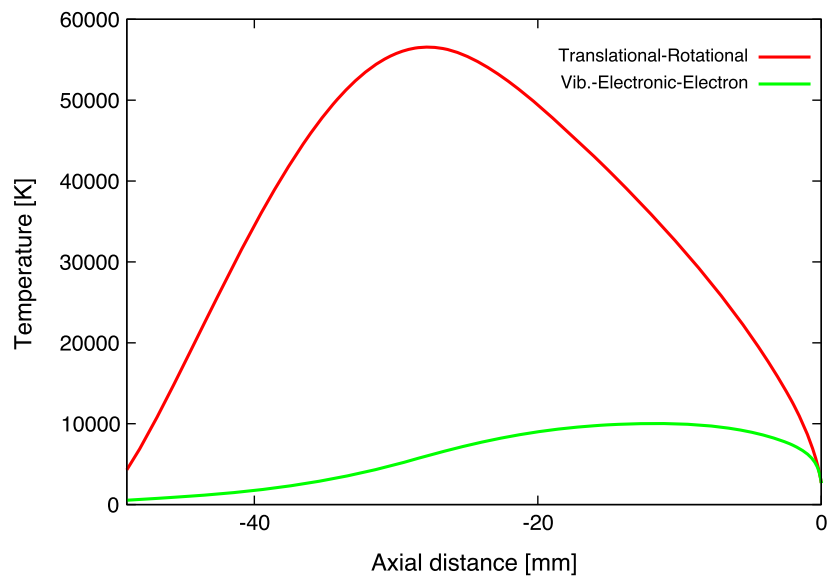

a) Stagnation line temperatures

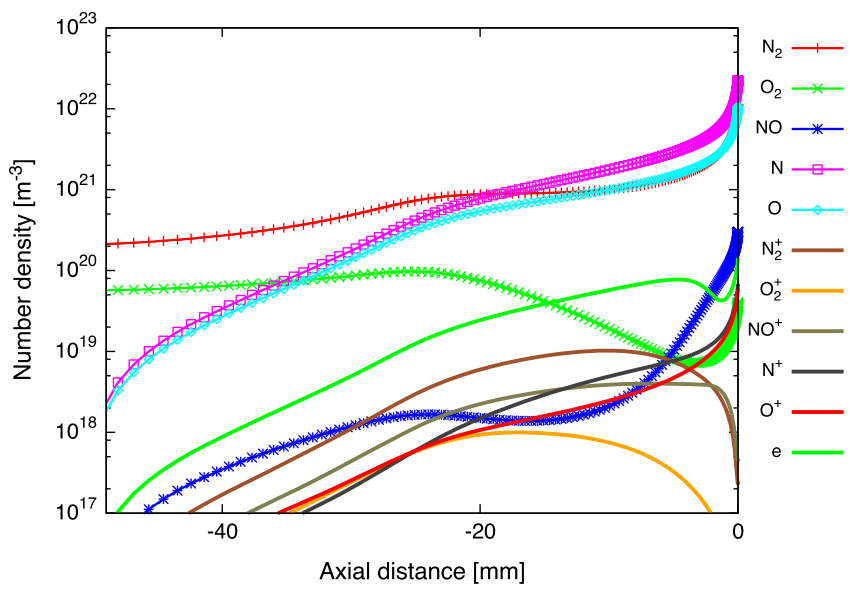

c) Air species

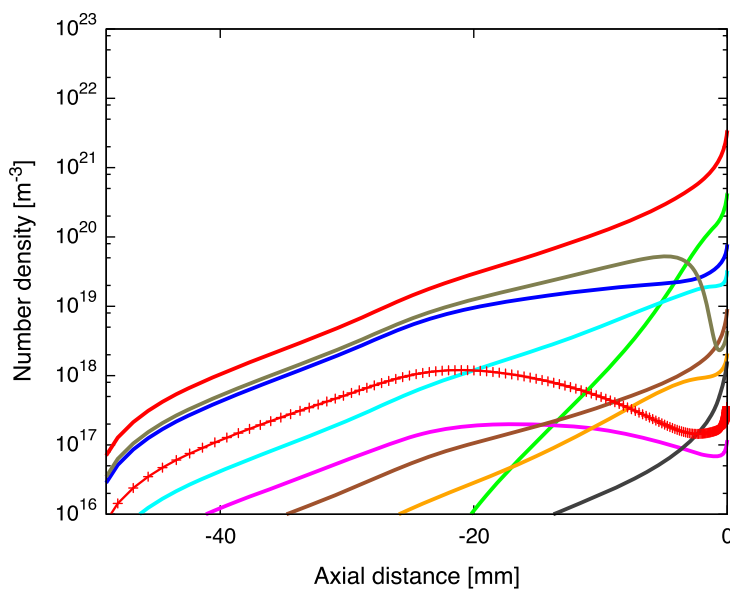

e) High concentration species side represents the convective flux approaching the wall from the the TPS domain. In all these equations, the blowing rate $\dot{m}_{w}^{\prime \prime}$, temperature $T$, and ablating species $Y_{g s}$ are imposed. The surface energy balance equation does not need to be solved in the present analysis.

Once values are computed for the primitive variables, the conservative quantities in the ghost cells of the boundary are set such that the flux across the wall is the required blowing flux. This blowing boundary condition has been tested over a wide range of blowing rates, assuring the robustness of the implementation. Following the same methodology for the verification and validation of NASA Ames's DPLR code [36] and NASA Langley's LAURA code

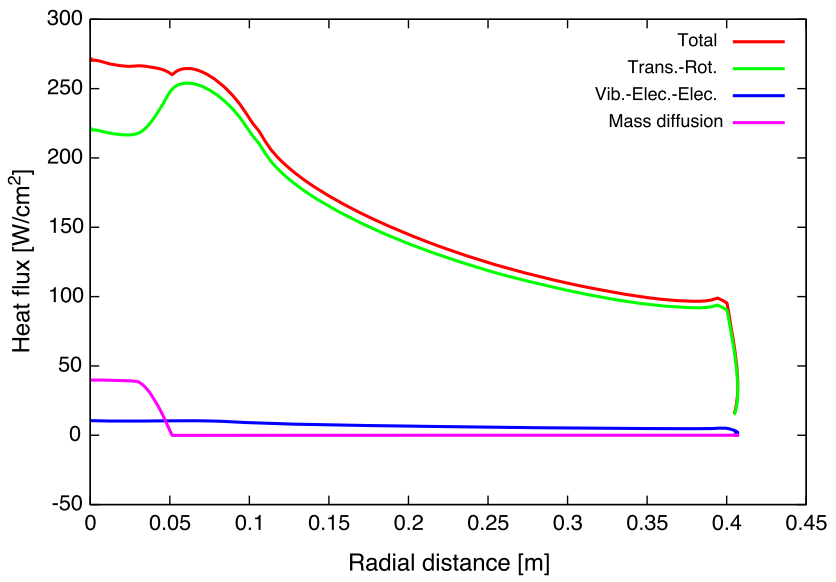

b) Surface heat fluxes

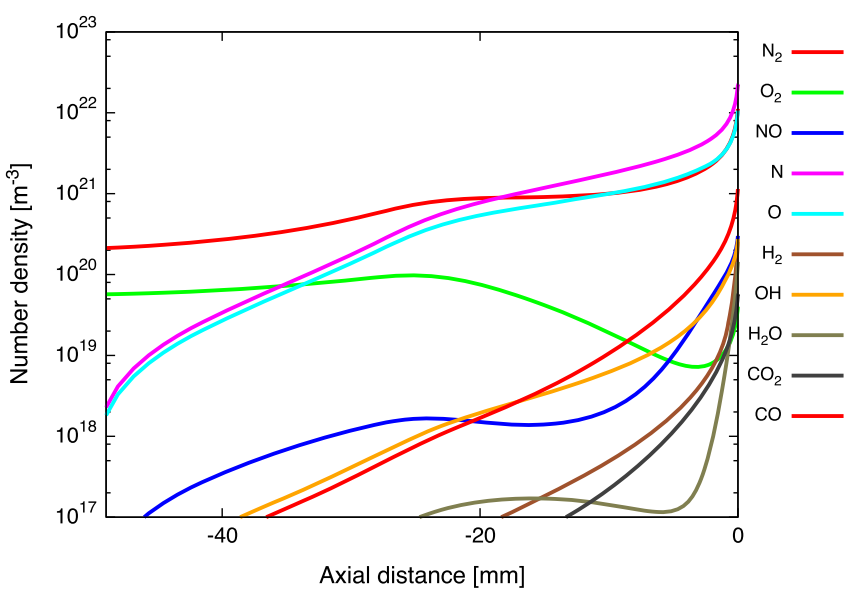

d) Surface blowing species

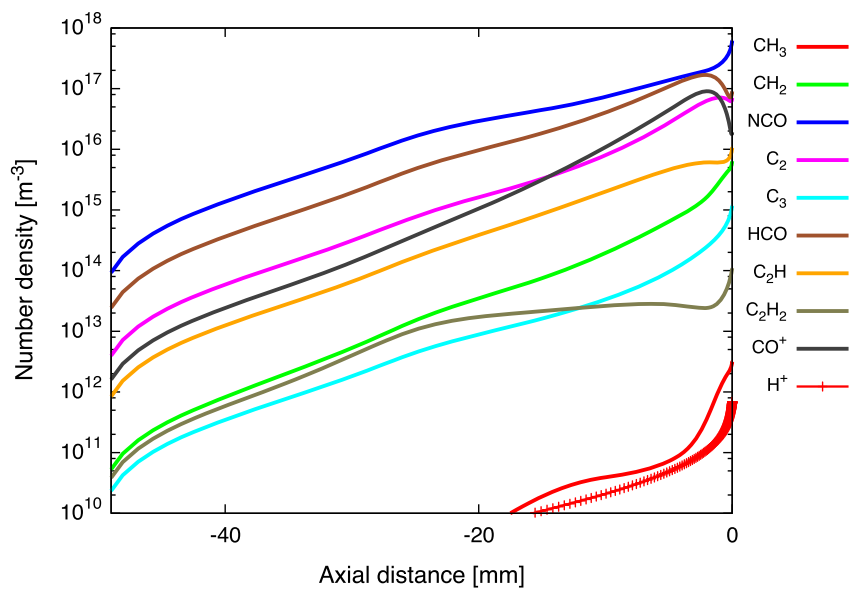

f) Low concentration species

Fig. 3 Stagnation line temperature, surface heat fluxes, and species concentrations along the stagnation line for the Stardust reentry vehicle at an altitude of $81 \mathrm{~km}(34 \mathrm{~s}$ into reentry). 
[37], the blowing boundary of LeMANS has also been verified and validated $[7,38]$. More details on these relations are provided in Ref. [39].

\section{Test Case: Stardust Return Capsule Reentry Trajectory}

\section{A. Problem Description}

To evaluate and validate the model in LeMANS, the forebody of the Stardust Return Capsule is modeled during the first $10 \mathrm{~s}$ of its reentry in the continuum regime [40]. These reentry points are chosen

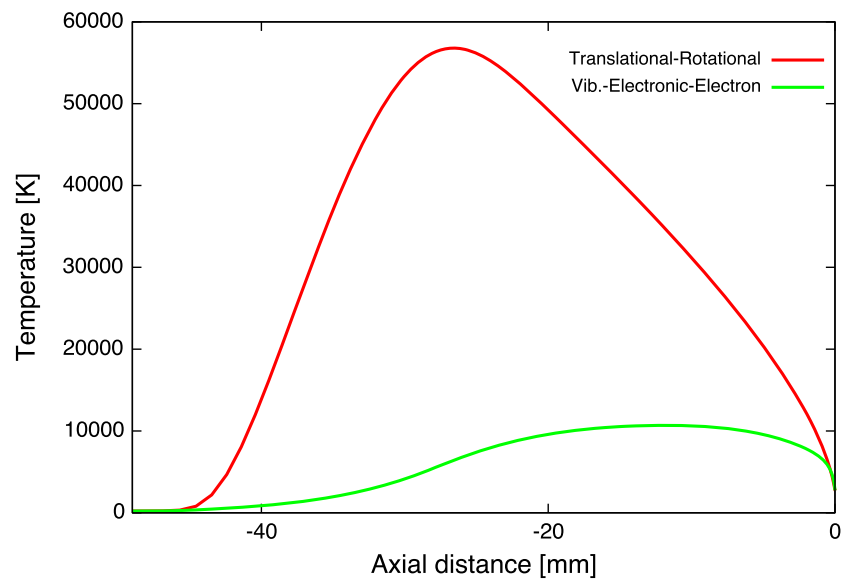

a) Stagnation line temperatures

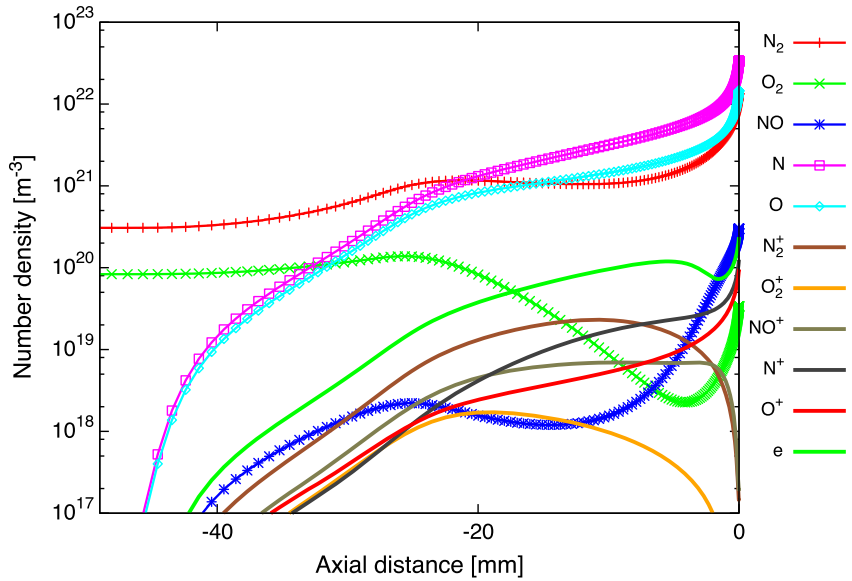

c) Air species

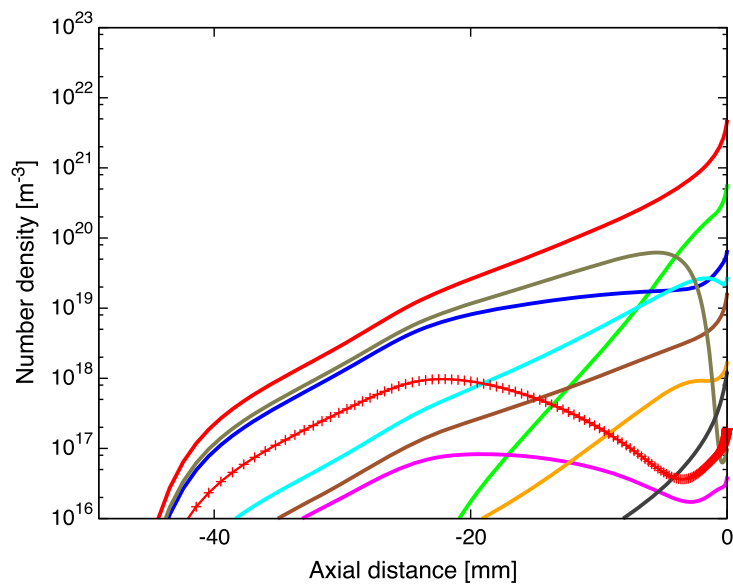

e) High concentration species because they also correspond to the period where spectral emission data were measured by the echelle instrument [41]. The echelle instrument is a miniature echelle spectrograph that operates at very high resolution of $0.14-0.9 \mathrm{~nm}$, over the range of 360 to $880 \mathrm{~nm}$. The instrument was installed onboard [41] a NASA observation airplane and was used to record emission spectroscopy of the reentry of the Stardust Return Capsule.

The geometry and mesh are presented in Fig. 1, and the flow and surface parameters in Tables $\underline{1}$ and $\underline{2}$, respectively. The flow field is computed with the previously defined 38 species chemistry model, with reaction rates listed in Ref. [13].

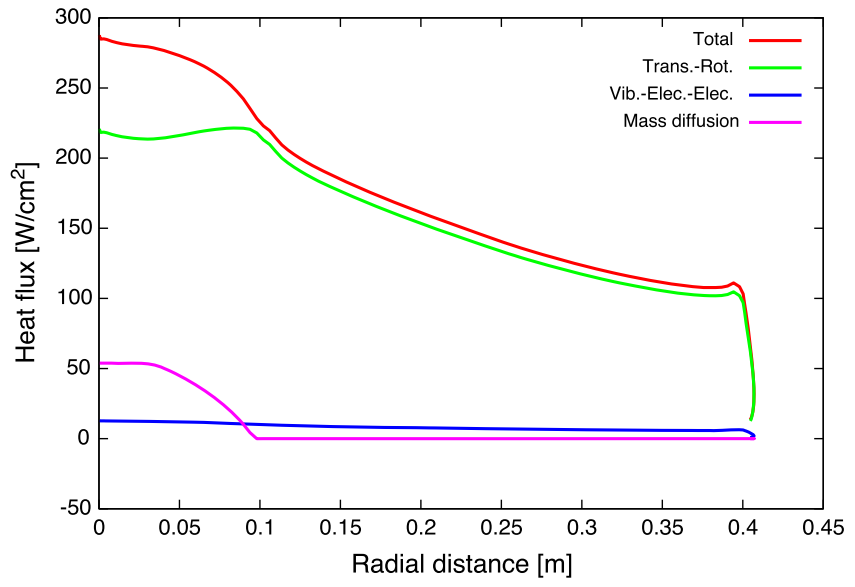

b) Surface heat fluxes

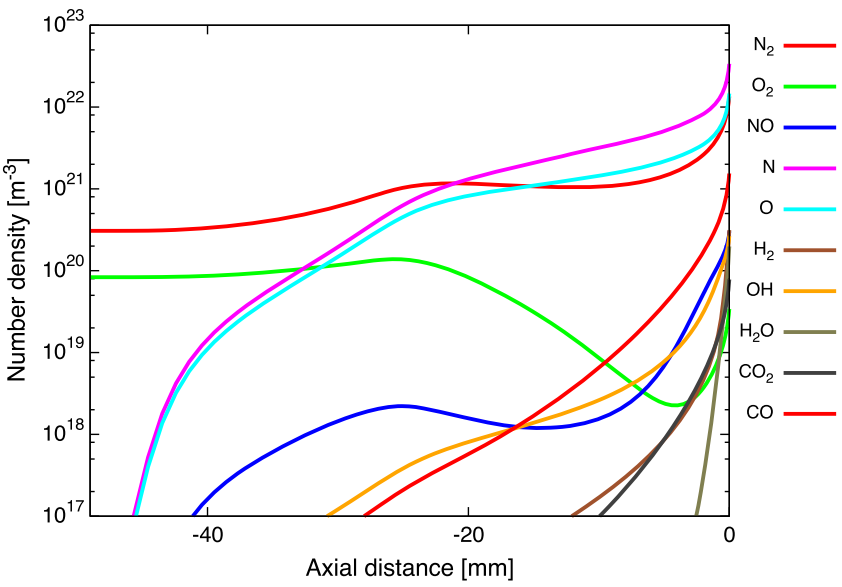

d) Surface blowing species

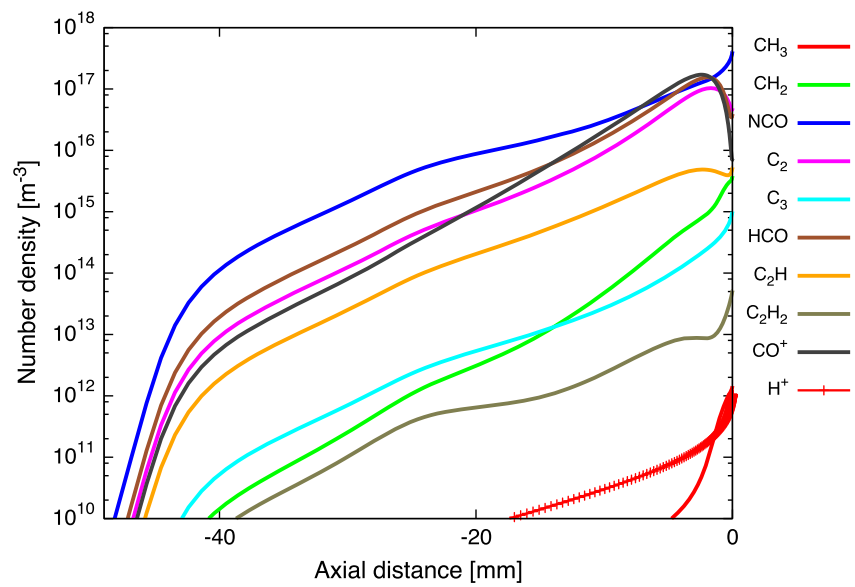

f) Low concentration species

Fig. 4 Stagnation line temperature, surface heat fluxes, and species concentrations along the stagnation line for the Stardust reentry vehicle at an altitude of $78.5 \mathrm{~km}$ (36 s into reentry). 
The values used for the surface temperature, blowing rates, and gas composition are listed in Table 2. The data were obtained through an uncoupled approach, using a combination of NASA codes, and are explained in great detail in Refs. $[11,12]$. In this approach, the surface balance equations are solved from the material response side and provide the temperature at the wall and gas composition at the wall.

The values obtained through this procedure are only calculated at the stagnation point and are expected to be significantly lower else-

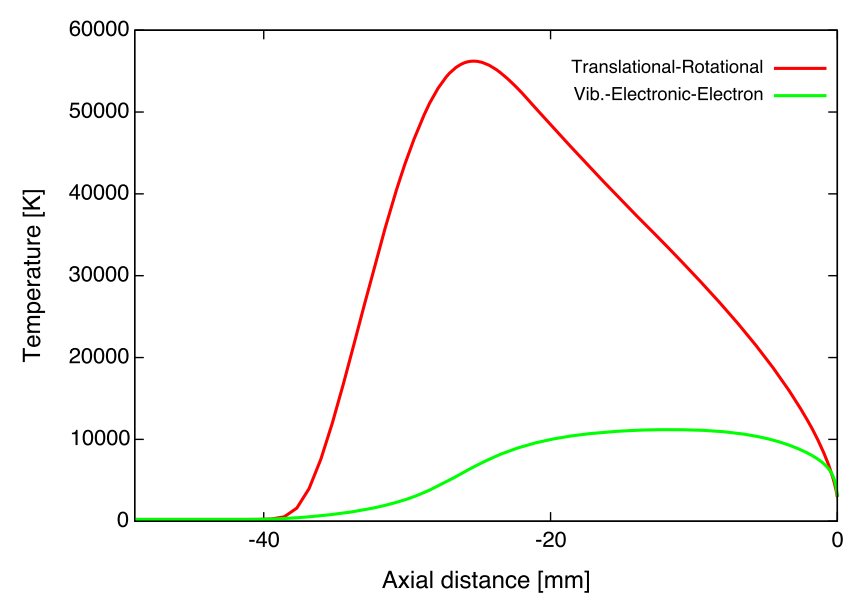

a) Stagnation line temperatures

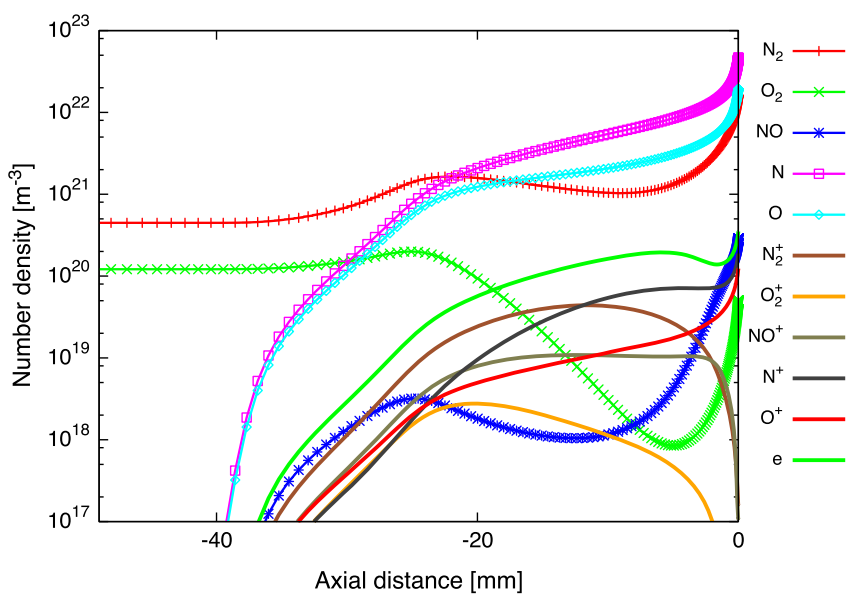

c) Air species

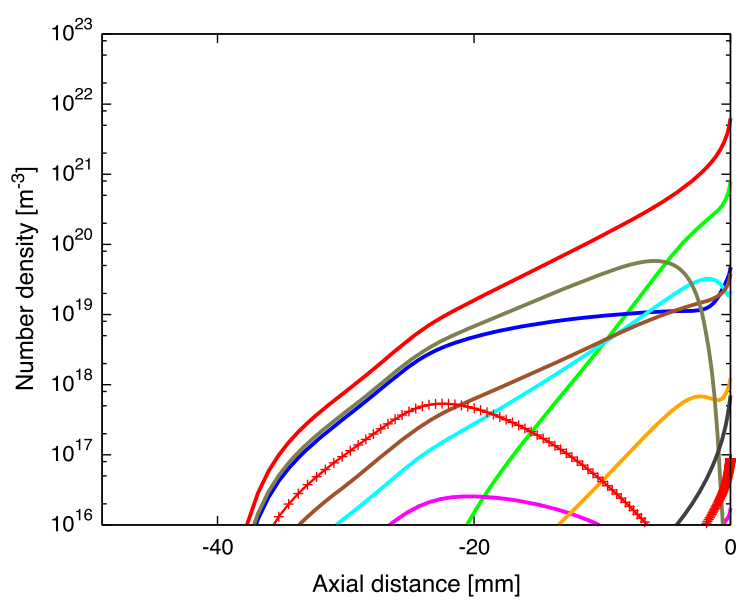

e) High concentration species where on the forebody of the vehicle. To reflect this, a temperature profile is obtained using a fully radiative equilibrium boundary condition at the wall, without ablation. The surface temperature profile is then normalized and reapplied for the ablating wall simulation via multiplication by the surface temperature at the stagnation point that is listed in Table 2 . This method has been proven to give a good estimate of the surface conditions [40]. For the blowing rate, a linear relation between the temperature and the mass flux is derived using the second and third columns of Table $\underline{2}$ and applied proportionally

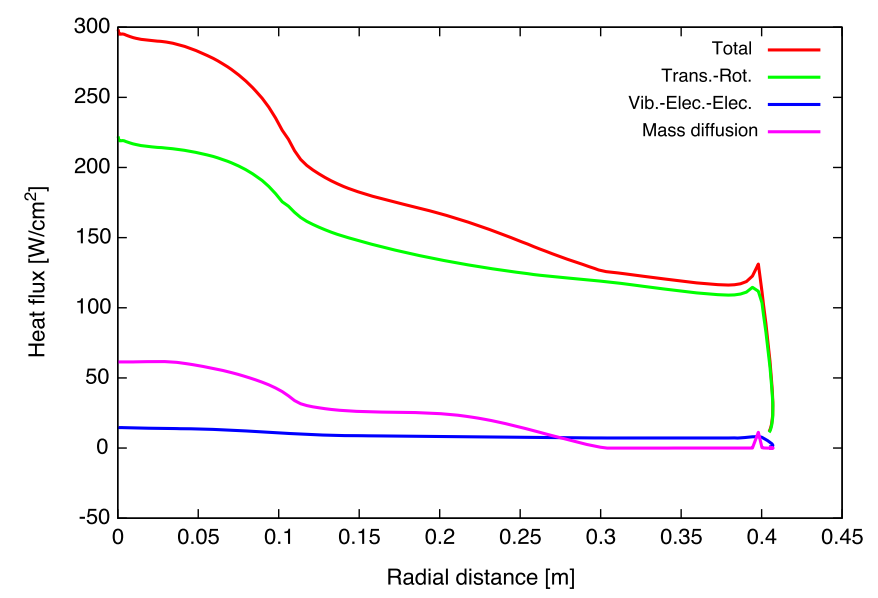

b) Surface heat fluxes

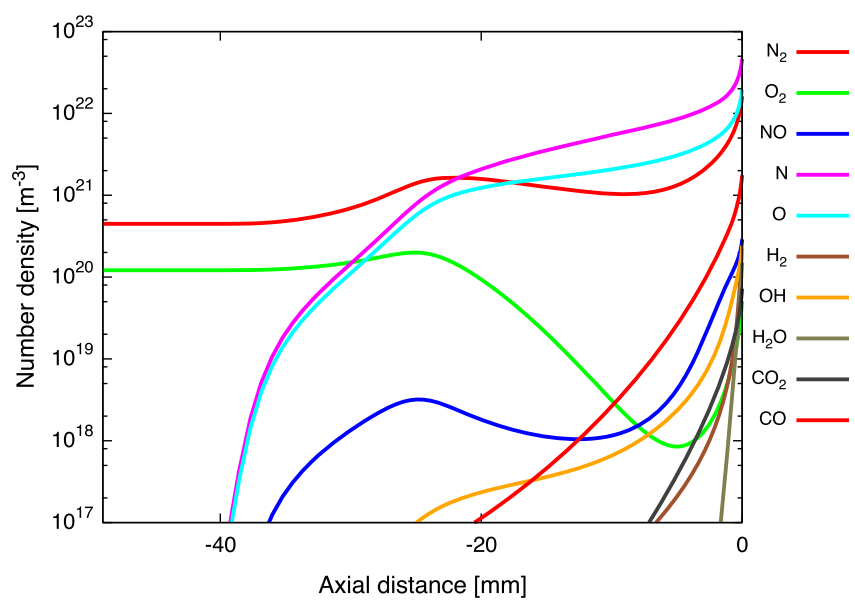

d) Surface blowing species

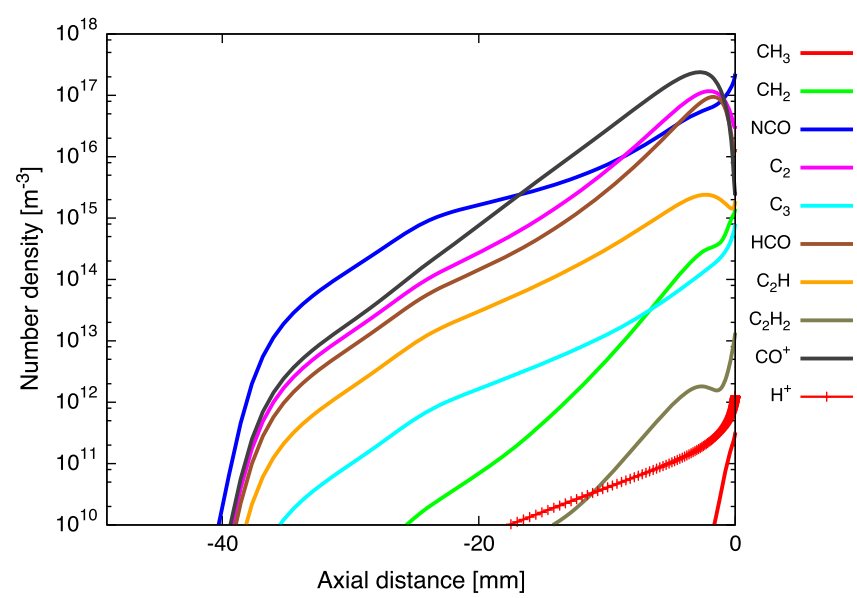

f) Low concentration species

Fig. 5 Stagnation line temperature, surface heat fluxes, and species concentrations along the stagnation line for the Stardust reentry vehicle at an altitude of $76 \mathrm{~km}(38 \mathrm{~s}$ into reentry). 
using the normalized surface temperature profile. For stability reason, when solving the momentum and mass balance equations, the mass flux goes to zero when the surface temperature goes below $2650 \mathrm{~K}$. The values for those two parameters are presented in Fig. 2.

\section{B. Results}

The stagnation line temperatures and gas composition as well as the heat flux components are presented in Figs. 3-8. Overall, for this

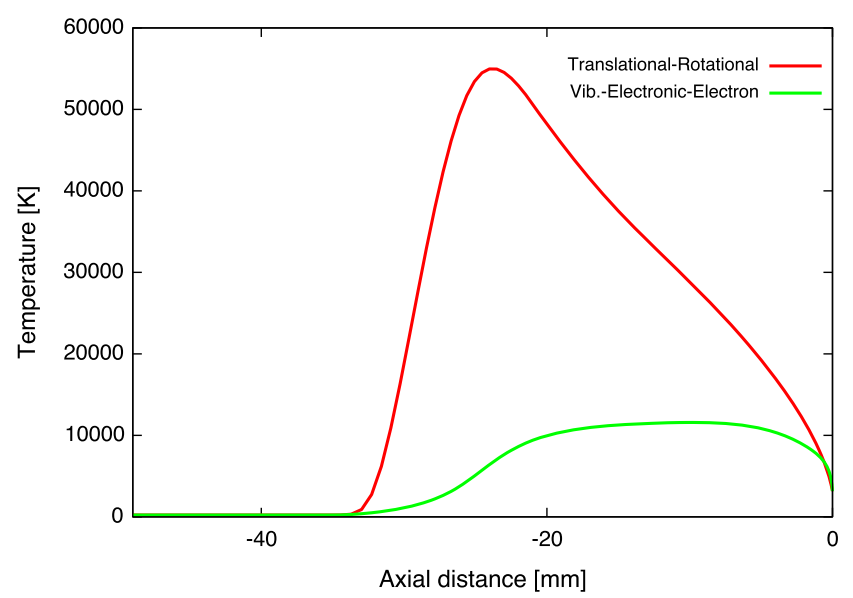

a) Stagnation line temperatures

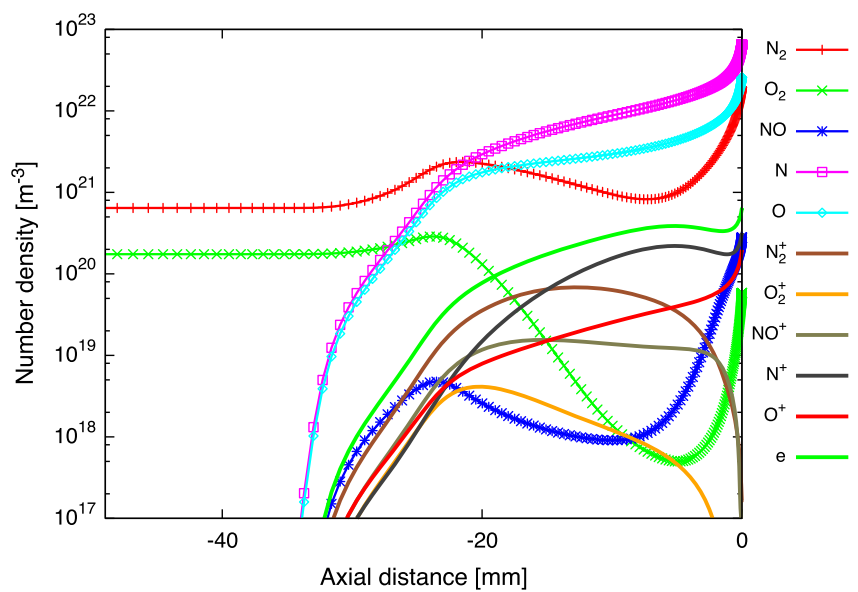

c) Air species

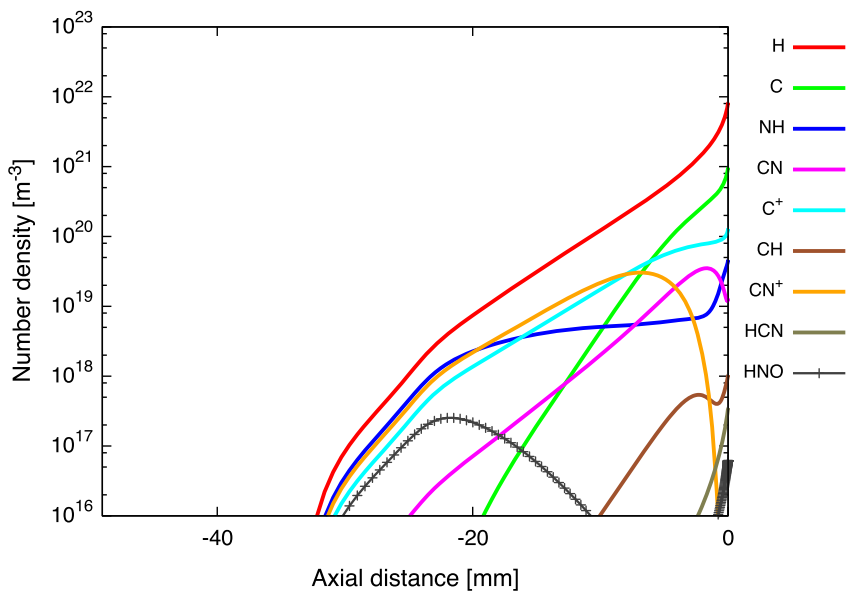

e) High concentration species particular trajectory, condition, and material, the various species behave in the same manners and are present along the same distance proportionally to the location of the shock. Most of the blowing species are destroyed almost immediately once they enter the flow, although $\mathrm{CO}$ and $\mathrm{OH}$ remain in relatively high concentration. These two species are important because they are strong radiators. Atomic species $\mathrm{H}$ and $\mathrm{C}$ are created in high concentration near the boundary, as are $\mathrm{CN}$ and $\mathrm{CN}^{+}$, which are also quite important due to their

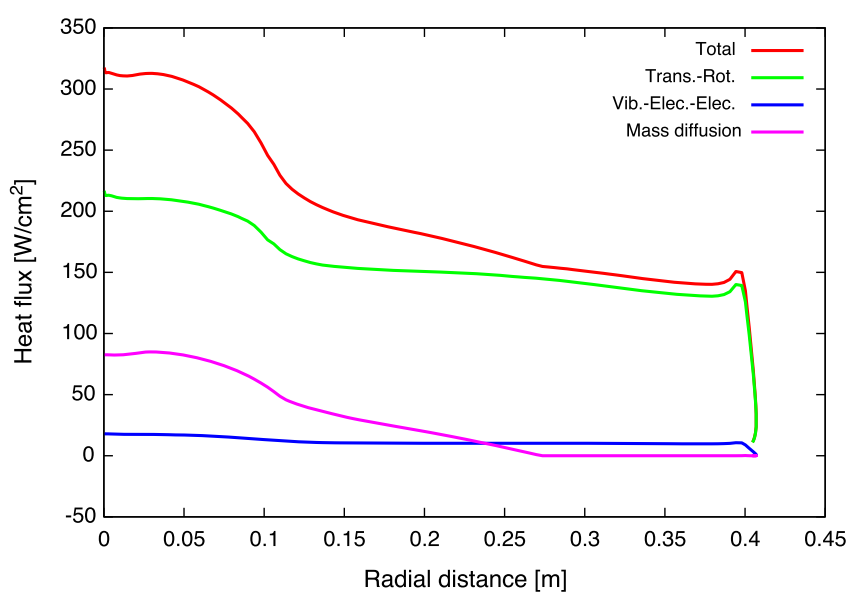

b) Surface heat fluxes

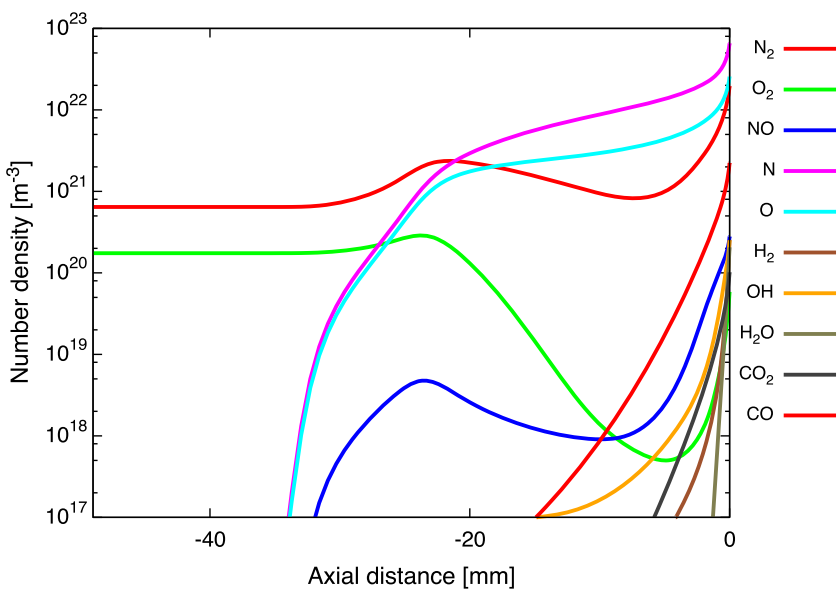

d) Surface blowing species

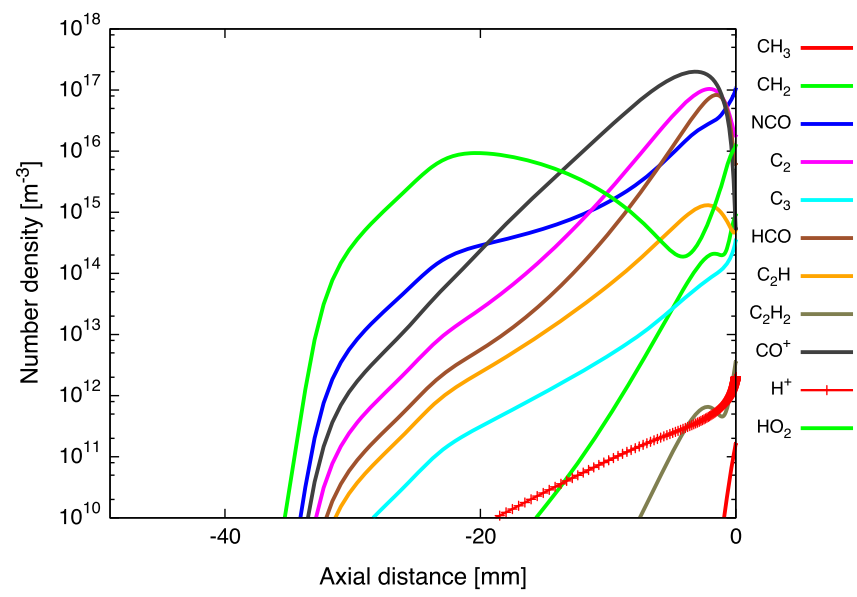

f) Low concentration species

Fig. 6 Stagnation line temperature, surface heat fluxes, and species concentrations along the stagnation line for the Stardust reentry vehicle at an altitude of $73.5 \mathrm{~km}(40 \mathrm{~s}$ into reentry). 
radiative properties. As noted previously $[\underline{12}, \underline{14}, \underline{15}]$, the concentration of HNO, a species neglected in other models, is relatively high.

The $71 \mathrm{~km}$ trajectory point is examined more closely. The Mach number over the whole computational is plotted on Fig. 9. On this figure, the shock can be clearly seen. The number density of the species identified as important in Fig. 7 are plotted over the domain in Figs. 10-12. In Fig. 10, it is interesting to notice that $\mathrm{H}$ and $\mathrm{C}$ remain at a fairly high concentration throughout the entire shock layer. As for $\mathrm{HNO}$ and $\mathrm{NH}$, they are both essentially created in the shock region

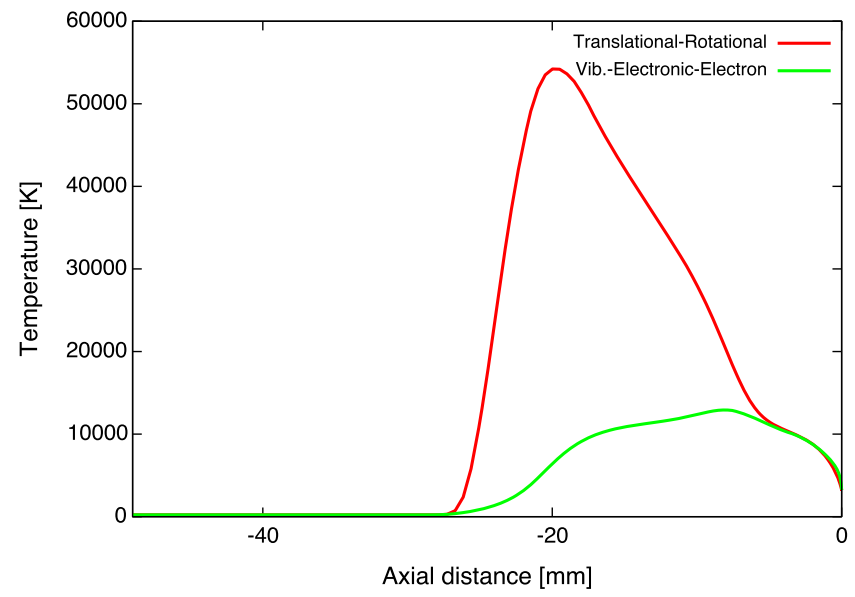

a) Stagnation line temperatures

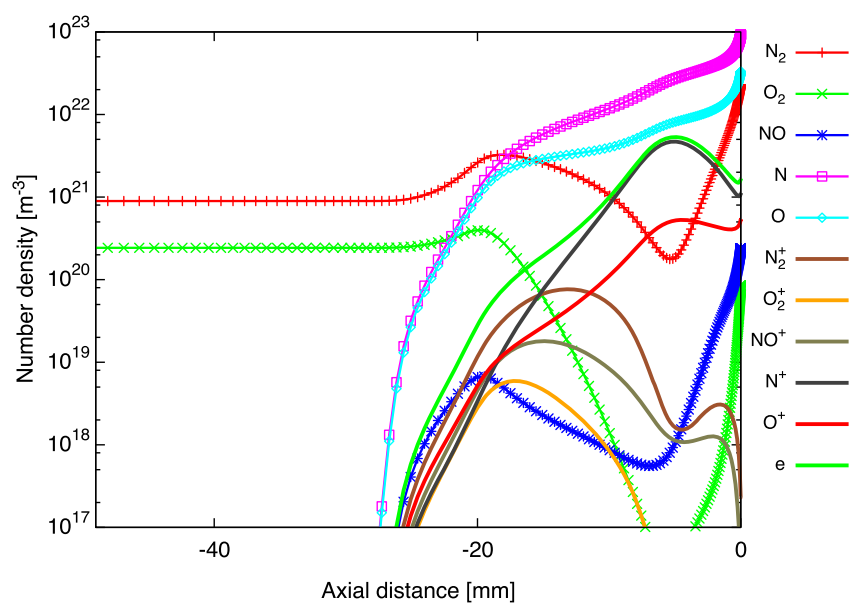

c) Air species

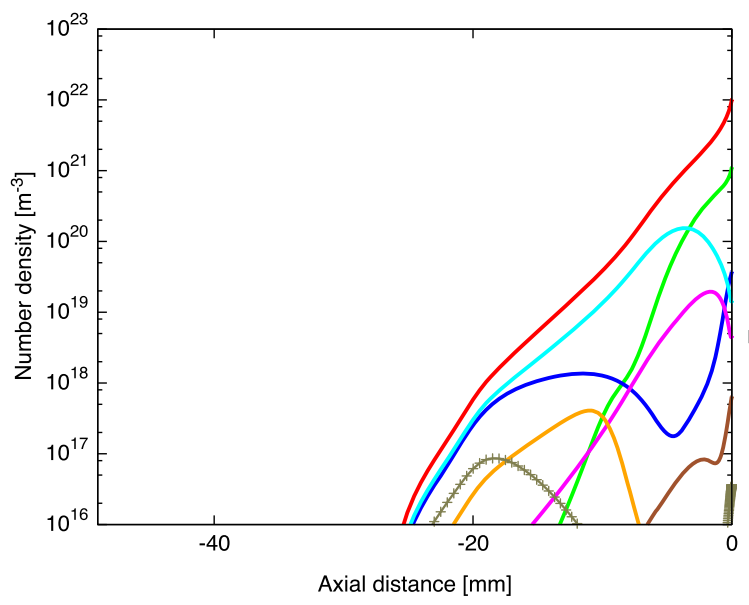

e) High concentration species and are present in substantial concentration. Both of these species were previously neglected in other carbon-phenolic-in-air chemistry models. The distribution of the $\mathrm{CO}$ and $\mathrm{CN}$ species are presented in Fig. 11. As can be seen, both $\mathrm{CO}$ and $\mathrm{CN}$ do not ionize near the stagnation region but do inonize farther along the body of the vehicle. This is an important observation because this ionization translates to a reduction of the $\mathrm{CN} / \mathrm{CO}$ concentration along the body, which is likely to affect the comparison to the echelle measurements (as seen in the next subsection). Finally, Fig. 12 presents the electron distribution as well as the $\mathrm{C}^{+}$distribution. $\overline{\mathrm{As}}$ with the other species, ionized $\mathrm{C}$

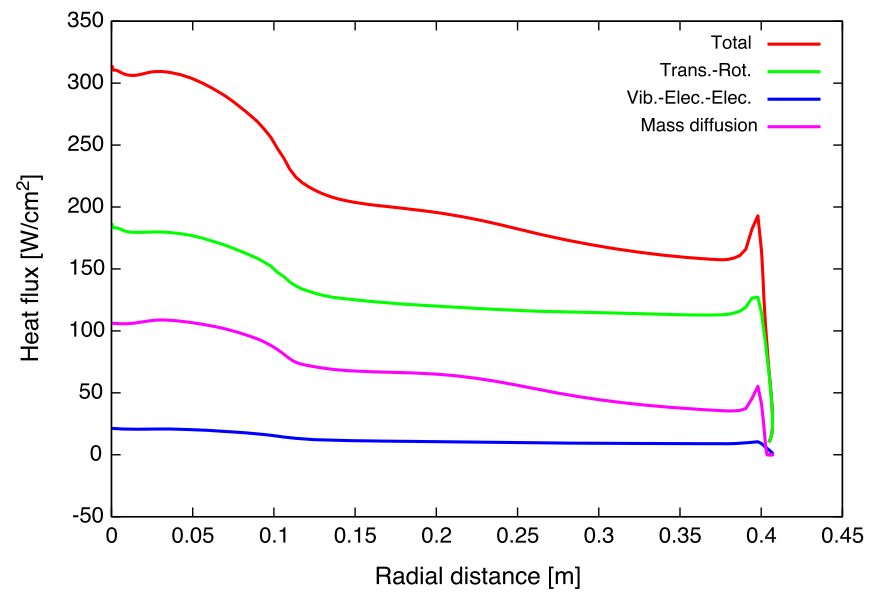

b) Surface heat fluxes

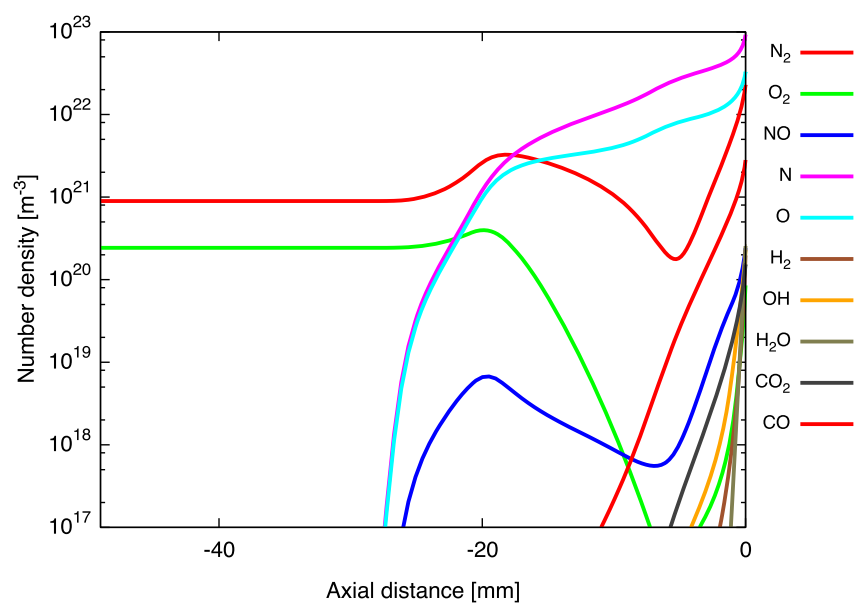

d) Surface blowing species

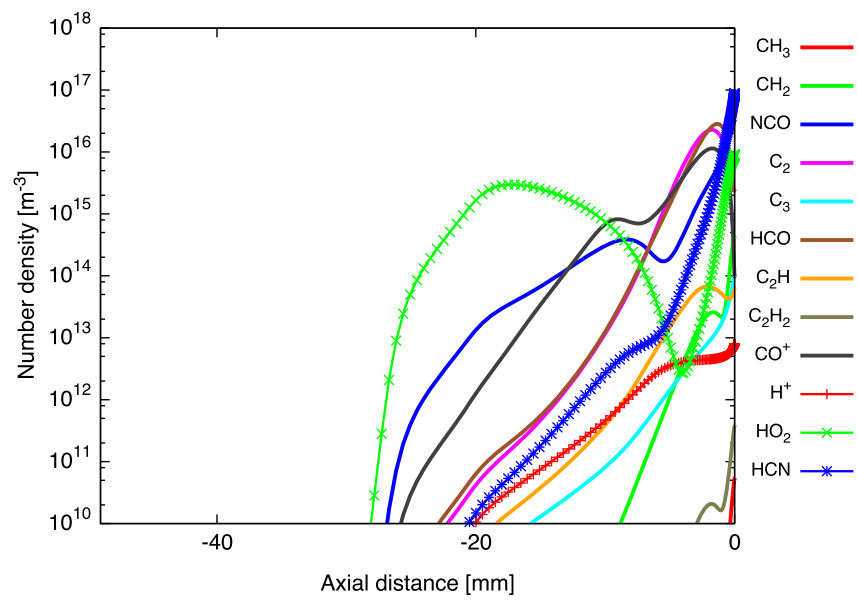

f) Low concentration species

Fig. 7 Stagnation line temperature, surface heat fluxes, and species concentrations along the stagnation line for the Stardust reentry vehicle at an altitude of $71 \mathrm{~km}$ (42 s into reentry). 
reaches its greatest concentration along the body, but not in the stagnation region, as is the case with $\mathrm{O}^{+}$and $\mathrm{N}^{+}$. The overall ion distribution can be evaluated by looking at the distribution of electrons. It is noted that $\mathrm{H}^{+}$, the only ion not presented in these graphs, only exists with a negligible concentration.

\section{Heat Flux Reduction}

To evaluate the heat flux reduction caused by the blowing of pyrolysis species from the surface, two additional series of test cases

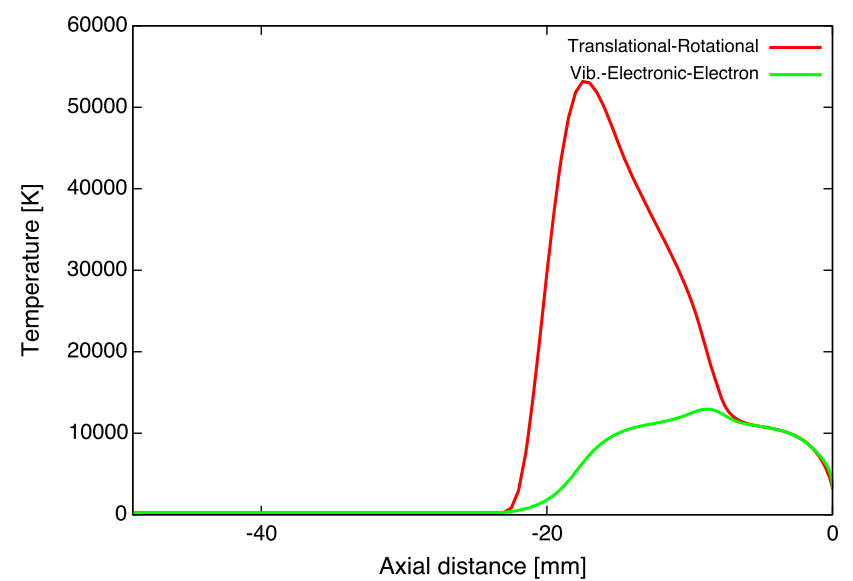

a) Stagnation line temperatures

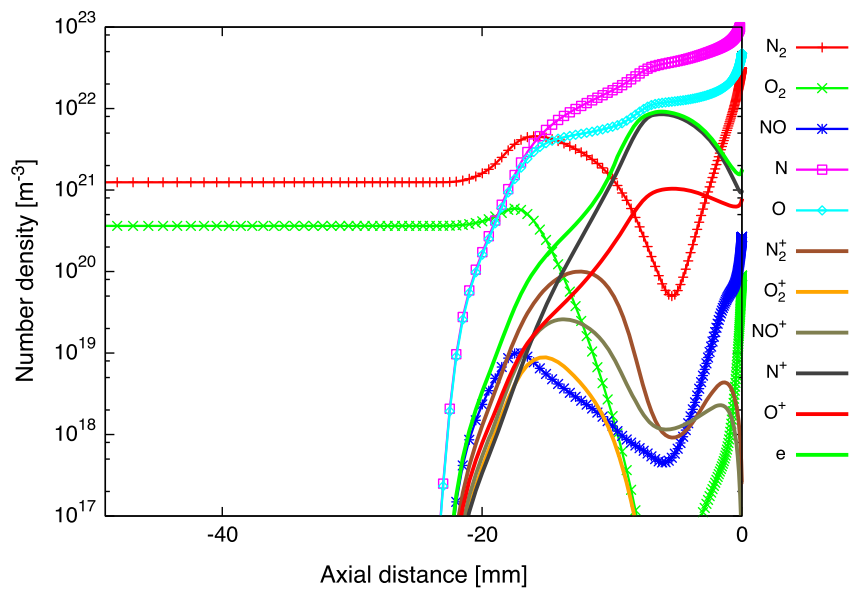

c) Stagnation line air species concentration

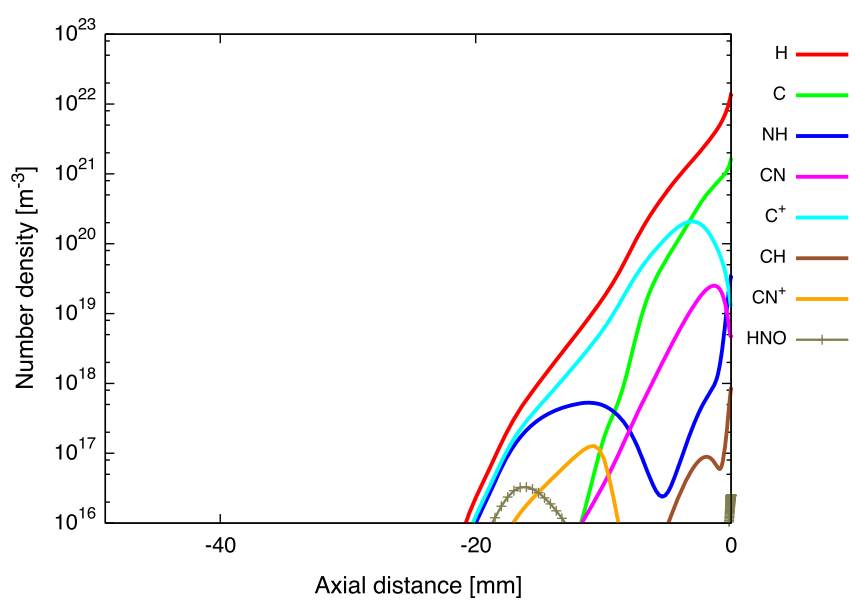

e) Stagnation line high concentration species are run for the echelle trajectory points. The first series uses a noncatalytic boundary condition, and the second uses a super catalytic one. Because a non-catalytic wall is known to underestimate the heat flux, and the super catalytic wall is known to overestimate, those two models provide a good starting point for comparisons. In both cases, an 11-species air chemistry model is used. The imposed surface temperature is the one listed in Table 2.

First, the blowing effect on the total surface heat flux is assessed by comparing the blowing boundary results to the super catalytic

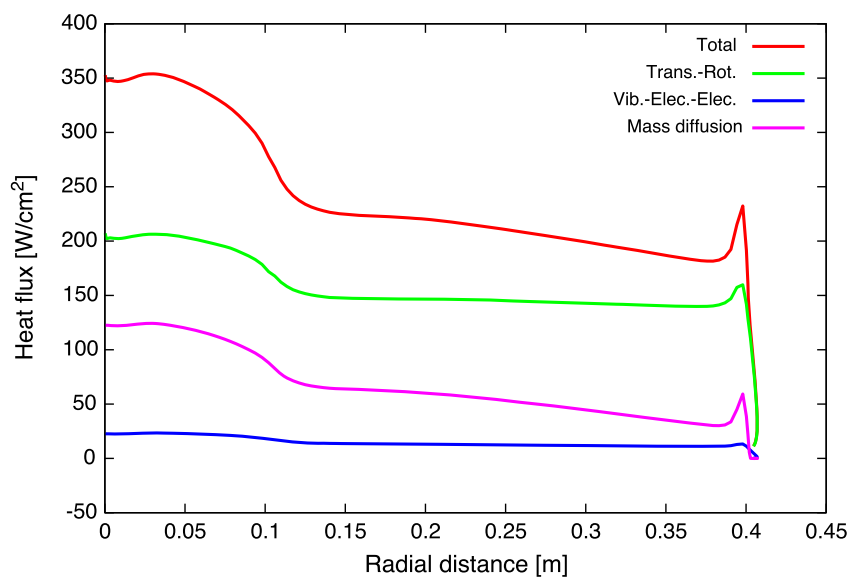

b) Surface heat fluxes

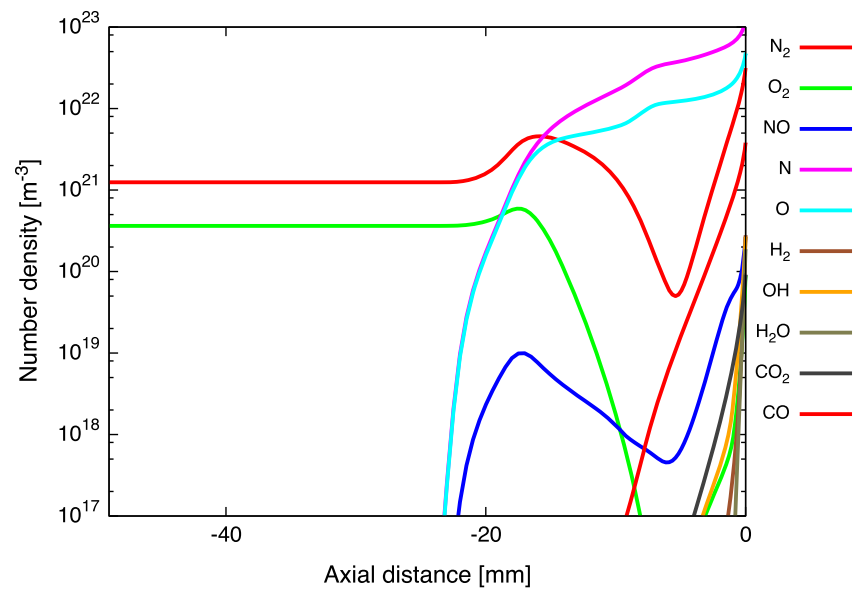

d) Stagnation line surface blowing species concentration

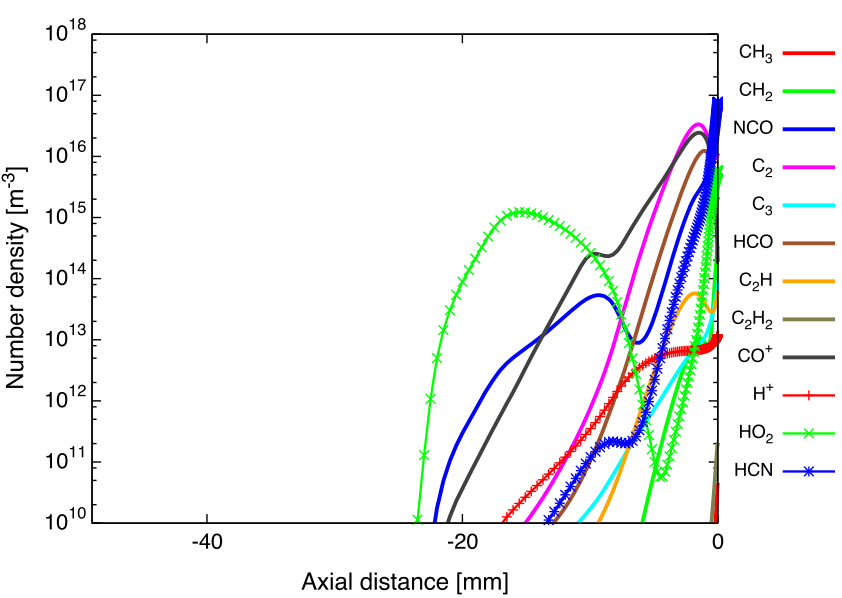

f) Stagnation line low concentration species

Fig. 8 Stagnation line temperature, surface heat fluxes, and species concentrations along the stagnation line for the Stardust reentry vehicle at an altitude of $68.9 \mathrm{~km}(44 \mathrm{~s}$ into reentry). 


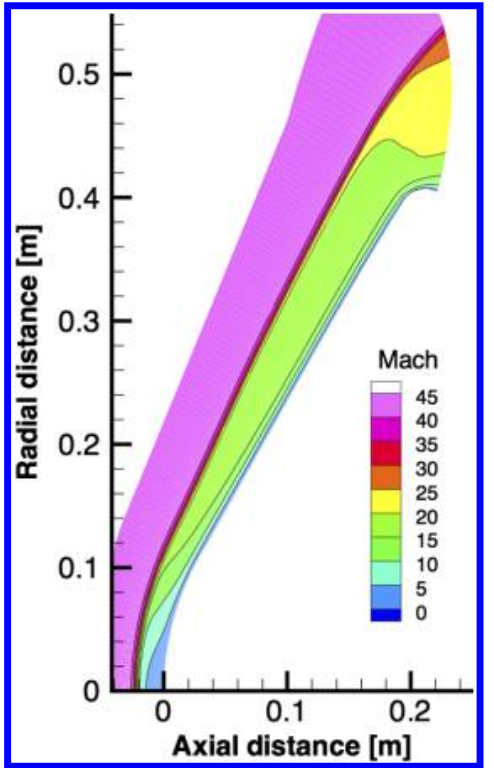

Fig. 9 Mach-number isolines for the Stardust vehicle at $71 \mathrm{~km}$ into reentry $(42 \mathrm{~s})$.
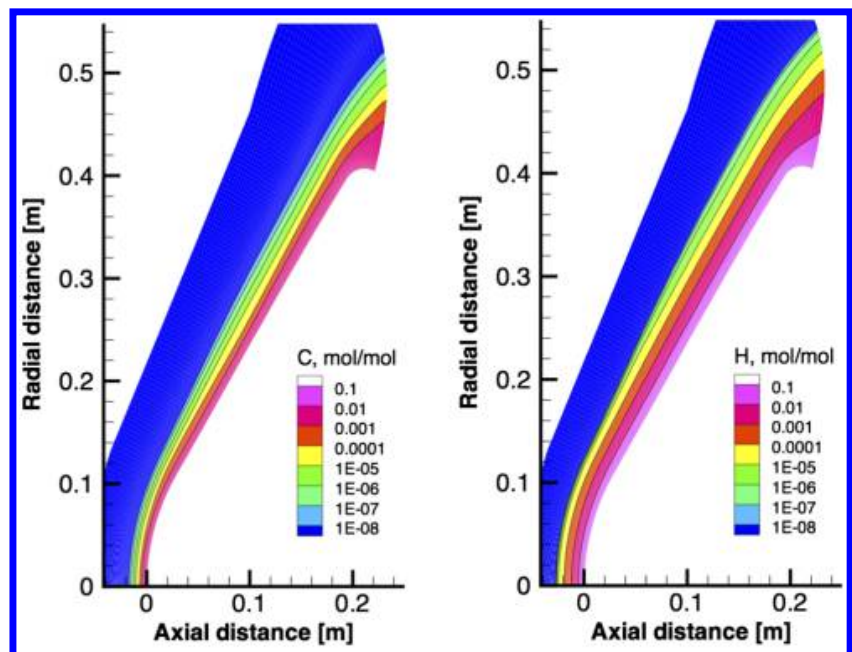

a) $\mathrm{C}$

b) $\mathbf{H}$
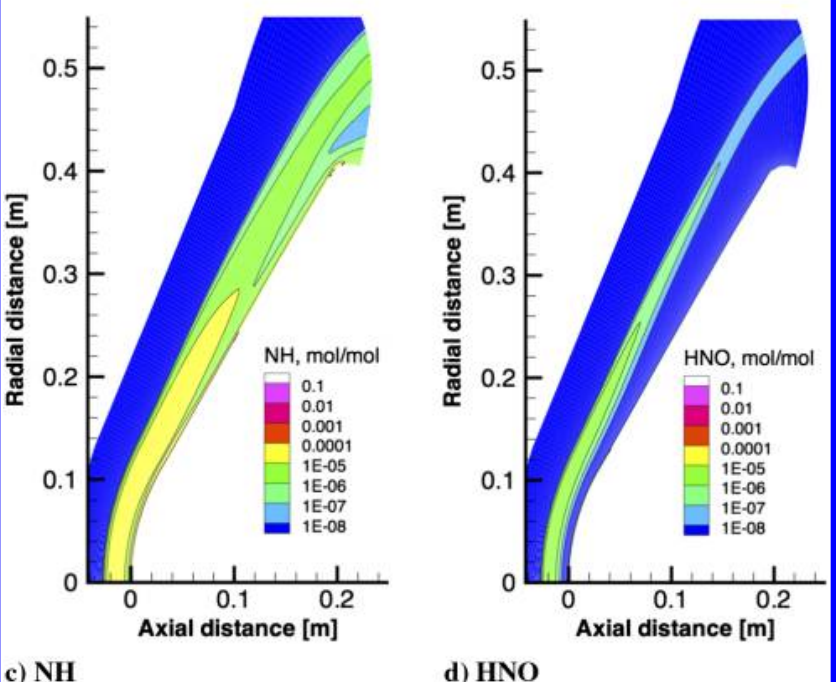

Fig. 10 Mole fraction isolines for some the species for the Stardust vehicle at $71 \mathrm{~km}$ into reentry $(42 \mathrm{~s})$. and non-catalytic ones for three of the trajectory points $(81,76$, and $68.9 \mathrm{~km}$ ). The total heat flux is defined as the sum of translational-rotational heat flux, vibrational-electronic-electron heat flux, and diffusion heat flux: $q_{\mathrm{tr}}, q_{\mathrm{ve}}$, and $h^{T} J$, respectively, from Eq. (3). The comparison is presented in Fig. 13; as expected, the heat flux for the blowing boundary condition is smaller than the noncatalytic heat flux, which is usually regarded as the lower bound when no ablation is present.

To understand the effects of the heat flux reduction, it is more suitable to look at the individual components of the heat flux one by one. Figure 14 presents the translational-rotational heat flux at the wall. Although the super-catalytic boundary condition provides a larger total heat flux (Fig. 13), the changes in composition of the boundary layer result in a significant reduction of the translationalrotational component. The same analysis can be performed on the vibrational-electron-electronic component of the heat fluxes (Fig. 15). As with $T_{\text {tr }}$, the changes in the chemical composition of the boundary layer result in a generalized reduction in the heat flux. However, the effects are not as straightforward as for the other conductive heat flux because the amount of species with vibrational (and electronic) degrees of freedom has a direct impact on the energy distribution.

The heat fluxes due to mass diffusion are shown in Fig. 16. As expected, the super-catalytic wall results in an artificially high heat flux, and those values are significantly reduced when a blowing boundary condition is applied. That figure also shows that the reduction in the translational-rotational heat fluxes is directly proportional
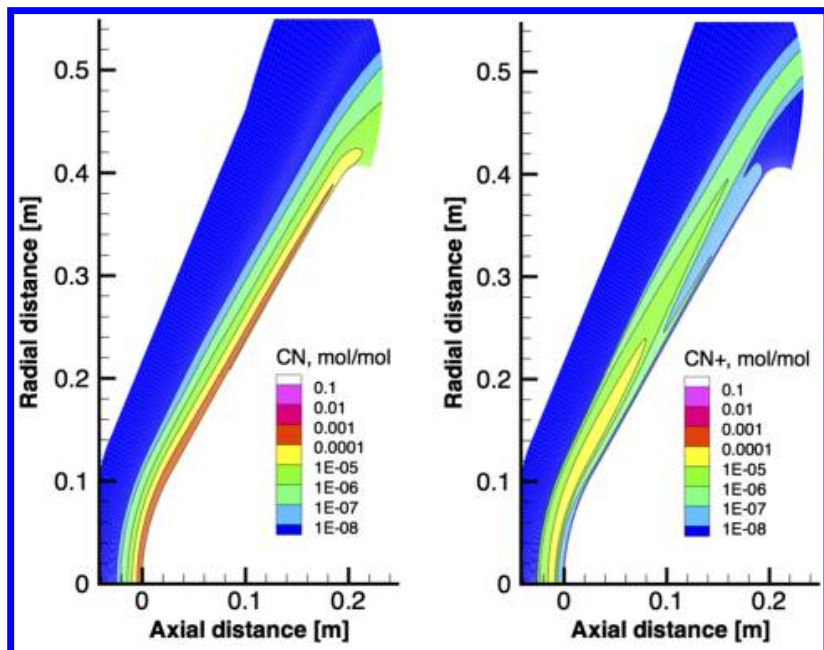

a) $\mathrm{CN}$

b) $\mathrm{CN}^{+}$
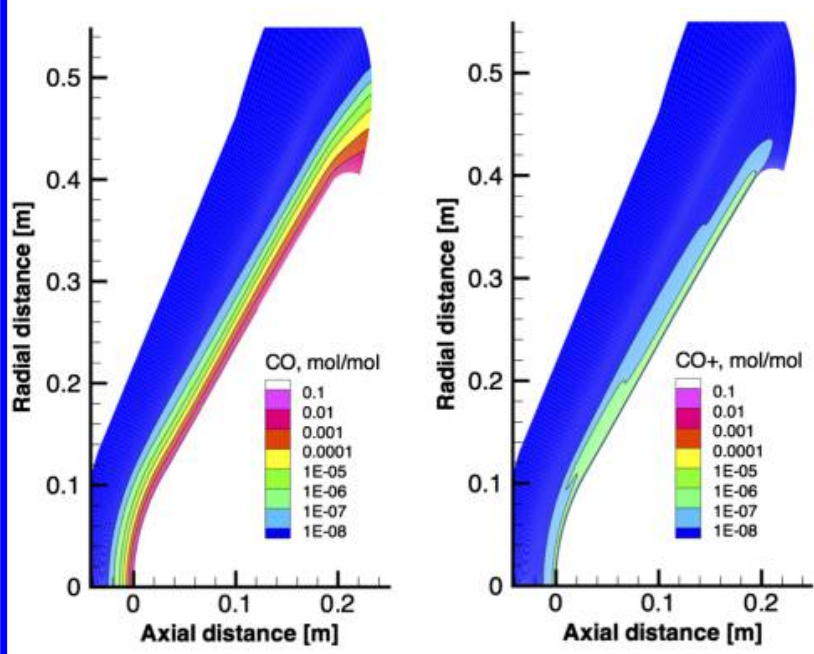

c) $\mathrm{CO}$

d) $\mathrm{CO}^{+}$

Fig. 11 Mole fraction isolines for some the species for the Stardust vehicle at $71 \mathrm{~km}$ into reentry $(42 \mathrm{~s})$. 


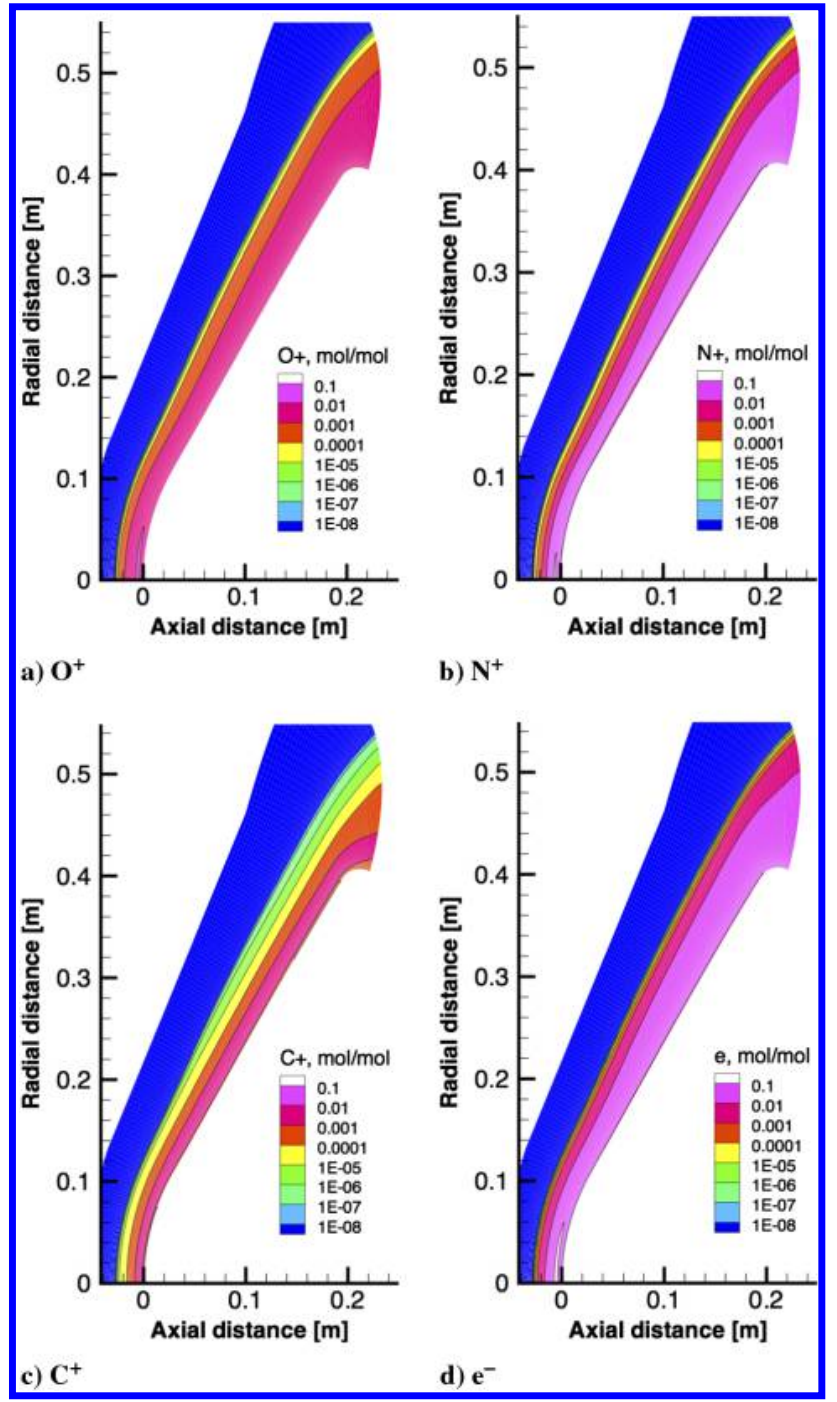

Fig. 12 Mole fraction isolines for some the species for the Stardust vehicle at $71 \mathrm{~km}$ into reentry $(42 \mathrm{~s})$. to the mass diffusion heat flux. By also comparing with Fig. 2b, it can be seen that the mass diffusion heat flux is directly proportional to the pyrolysis gas mass flow.

Finally, in Fig. 17, the relative contributions of each component of the heat flux are plotted for all trajectory points. It can be seen that, for the trajectory points chosen for this analysis, the translationalrotational component contributes the most. We can also observe that the amount of blowing has a direct and linear influence on the translational-rotational heat flux. This result clearly shows that an increase in blowing rates has a major impact on the overall heat flux and that, although it translates into an increase in mass diffusion heat flux, it does not become the dominant component.

Next, the effects of ablation blowing on translational-rotational energy are examined. Figures 18-20 present the translationalrotational temperature, the vibrational-electronic-electron temperature, and the pressure on the stagnation line, respectively. As can be seen in Fig. 20, the first notable effect of blowing is the displacement of the shock. Even at low blowing rates $(81 \mathrm{~km})$, the shock is significantly moved away from the surface of the vehicle. This has, of course, a direct repercussion on the shape of the temperature curves and therefore affects the gradient of temperature at the wall, as can be seen in Fig. 18 and 19 . However, even if the heat flux is directly linked to the gradient of temperature at the wall [see Eq. (4)], the gas-phase thermal conductivity also plays an important role. It is for that reason that the results show no direct correlation with the steepness of the gradient and the heat flux. The steepest curves shown in Fig. 18 are the ones associated with super-catalytic boundary condition; however, as can be seen in Fig. 14, the higher translational-rotational heat fluxes are the ones associated with the non-catalytic boundary condition. It therefore appears that, regardless of the altitude, blowing rate, and chemical species, the most important effect that contributes to heat flux reduction is most likely the composition of the gas in the boundary layer.

\section{Radiative Emission}

Certain species present in the boundary layer are strong radiative emitters and are expected to significantly contribute to the overall radiative heat flux at the surface. For the Stardust reentry vehicle, the contribution of the radiative heat flux to the overall heat flux has been evaluated, at maximum intensity, to be approximately $10 \%$ [40].

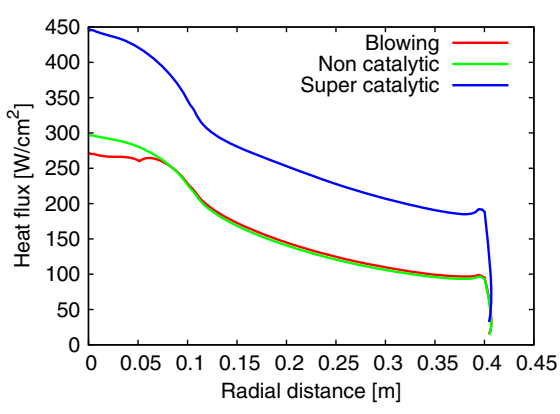

a) Reentry altitude of $81 \mathrm{~km}$

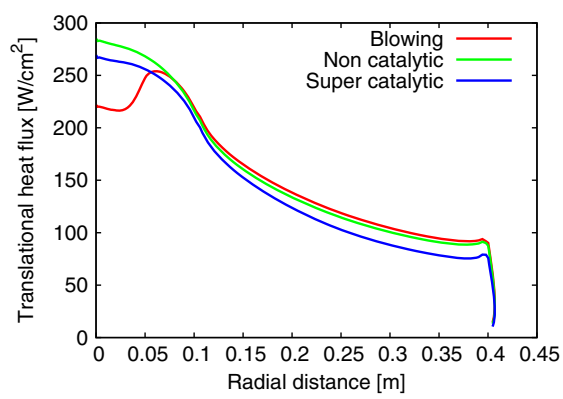

a) Reentry altitude of $81 \mathrm{~km}$

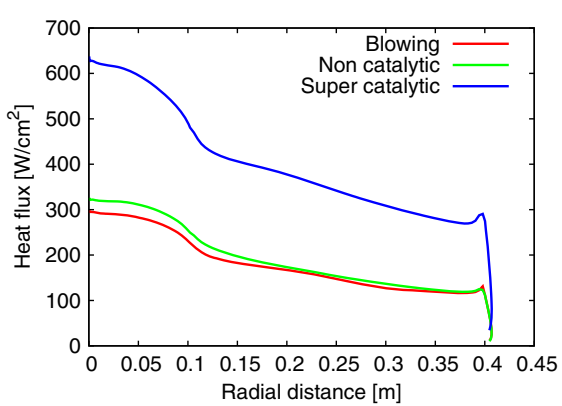

b) Reentry altitude of $76 \mathrm{~km}$

Fig. 13 Blowing effects on the total heat flux.

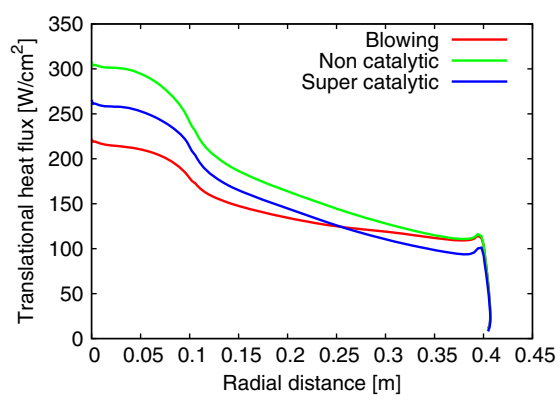

b) Reentry altitude of $76 \mathrm{~km}$

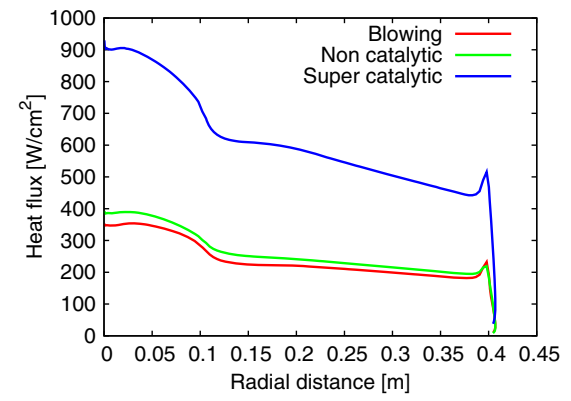

c) Reentry altitude of $68.9 \mathrm{~km}$

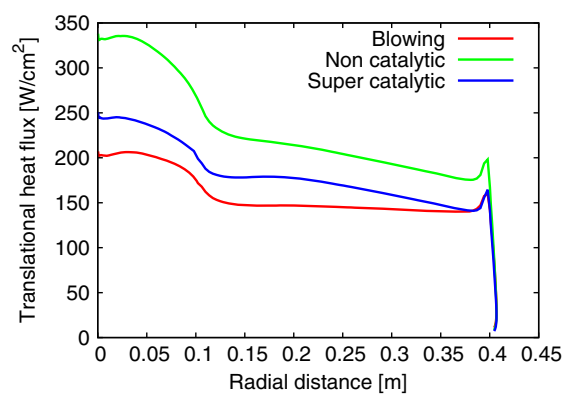

c) Reentry altitude of $68.9 \mathrm{~km}$

Fig. 14 Blowing effects on the translational-rotational heat flux. 


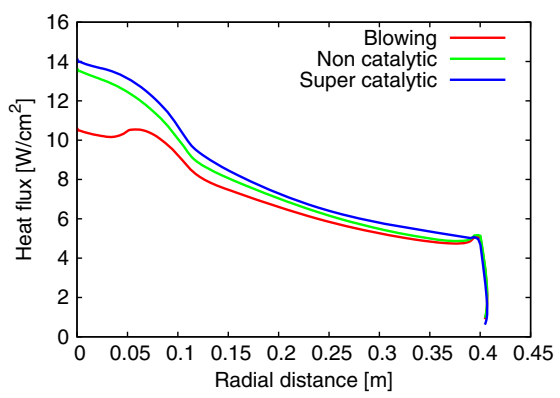

a) Reentry altitude of $81 \mathrm{~km}$

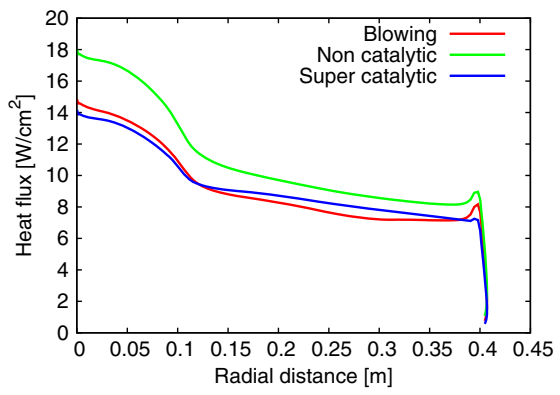

b) Reentry altitude of $76 \mathrm{~km}$

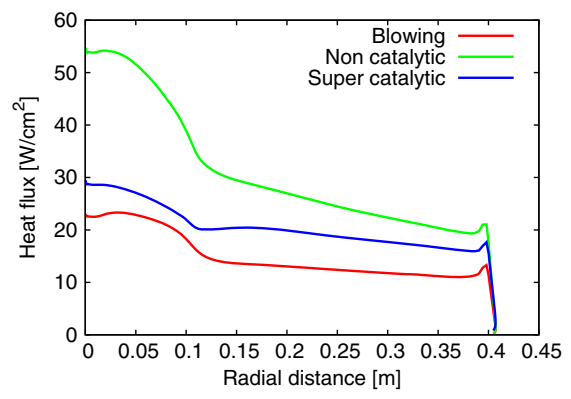

c) Reentry altitude of $68.9 \mathrm{~km}$

Fig. 15 Blowing effects on the vibrational-electronic-electron heat flux.

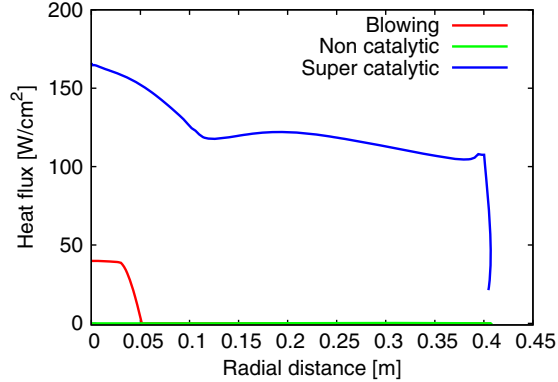

a) Reentry altitude of $81 \mathrm{~km}$

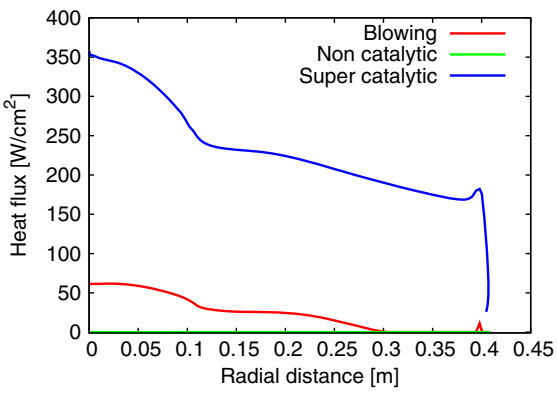

b) Reentry altitude of $76 \mathrm{~km}$

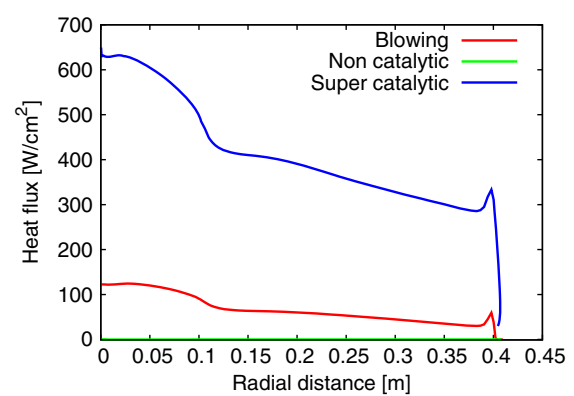

c) Reentry altitude of $68.9 \mathrm{~km}$

Fig. 16 Blowing effects on the mass diffusion heat flux.

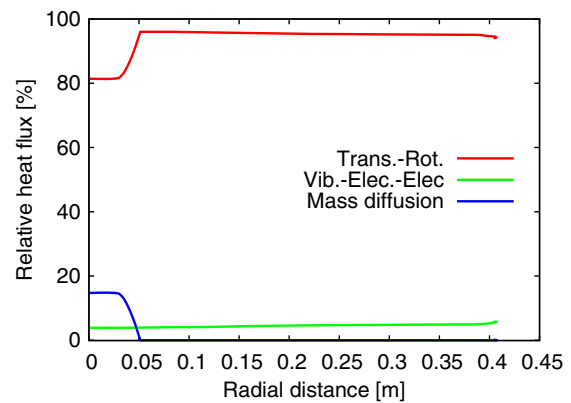

a) Reentry altitude of $81 \mathrm{~km}$

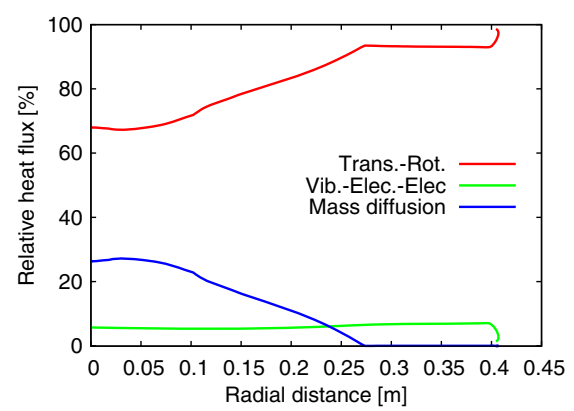

d) Reentry altitude of $73.5 \mathrm{~km}$

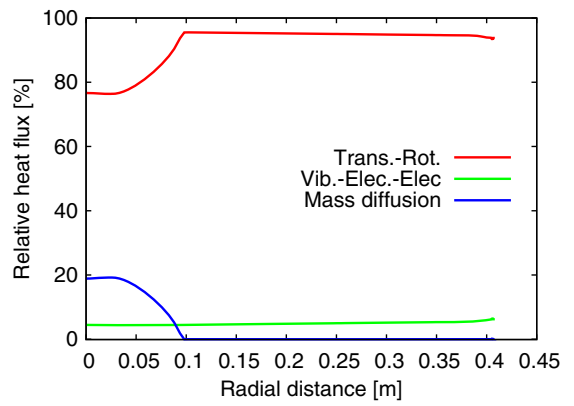

b) Reentry altitude of $78.5 \mathrm{~km}$

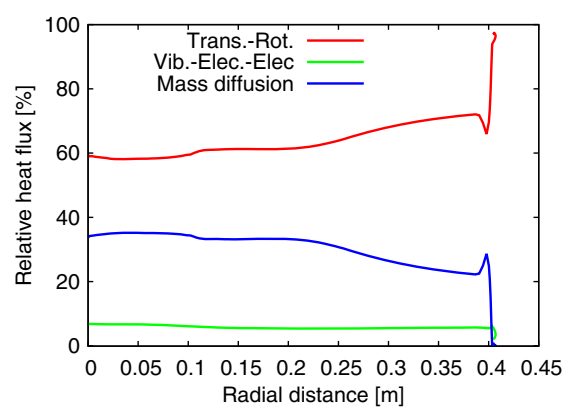

e) Reentry altitude of $71.2 \mathrm{~km}$

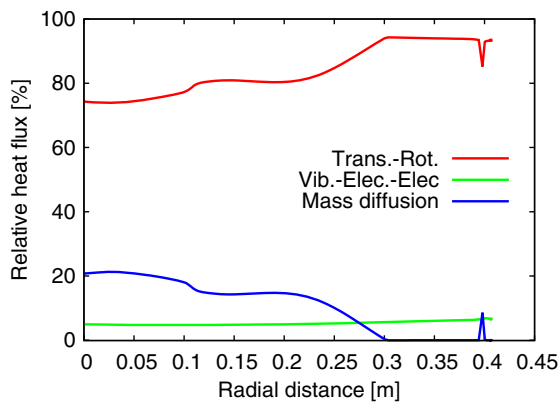

c) Reentry altitude of $76 \mathrm{~km}$

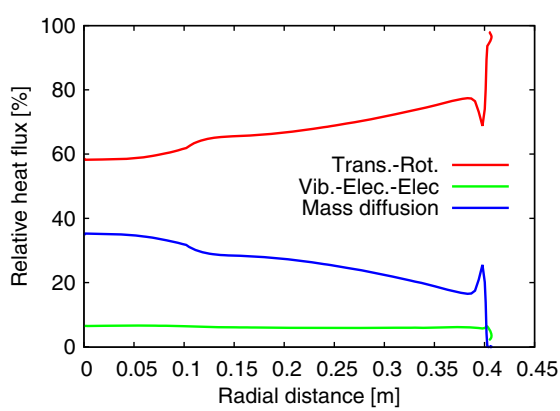

f) Reentry altitude of $68.9 \mathrm{~km}$

Fig. 17 Relative contribution of individual components of the heat flux using the blowing boundary condition.

A radiative emission calculation is performed using the flow field solution of the $42 \mathrm{~s}$ trajectory point $(71 \mathrm{~km})$, with the NEQAIR 12 (version 7) [16] non-equilibrium radiation code. Apart from the usual air species, radiative emission from the $\mathrm{CN}$ violet and $\mathrm{CN}$ red systems is included (see Table $\underline{3}$ ).

The temperatures and species concentrations used as inputs to NEQAIR are presented in Figs. 21 and 22. Because the echelle data have no spatial resolution, the computed spectra need to be spatially averaged over the front surface using multiple lines parallel to the symmetry line. The lines used are located at $r=0,0.20,0.30$, and $0.42 \mathrm{~m}$. The last line does not intersect with the surface, which explains why the temperatures are not at equilibrium on the righthand side of Fig. 22c and why Fig. 22d does not have the same general behavior as the other density plots.

From the density plots presented in Figs. 21 and 22 , it is interesting to note that $\mathrm{CN}^{+}$plays a more significant role in the determination of the species concentrations than was previously thought. It is created at the cost of $\mathrm{CN}$ and therefore reduces the $\mathrm{CN}$ concentration by up to 


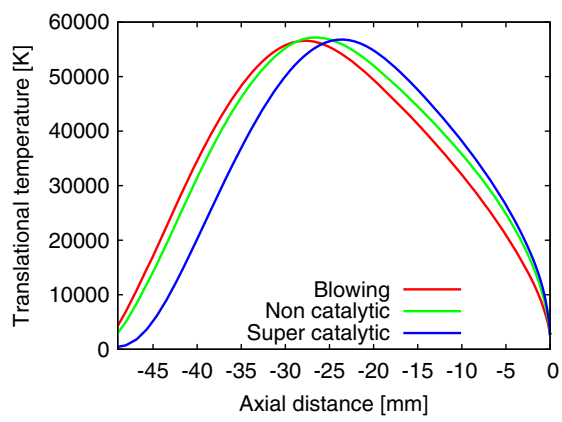

a) Reentry altitude of $81 \mathrm{~km}$

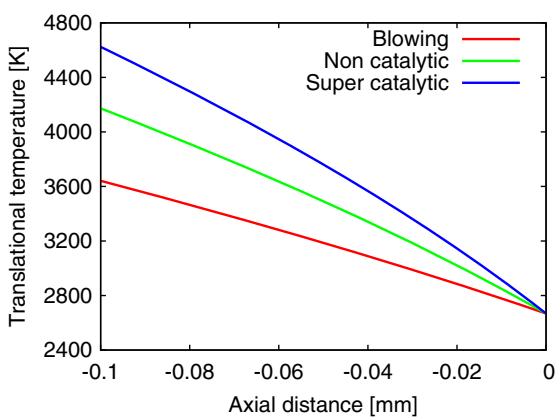

d) Reentry altitude of $81 \mathrm{~km}$ (near the wall)

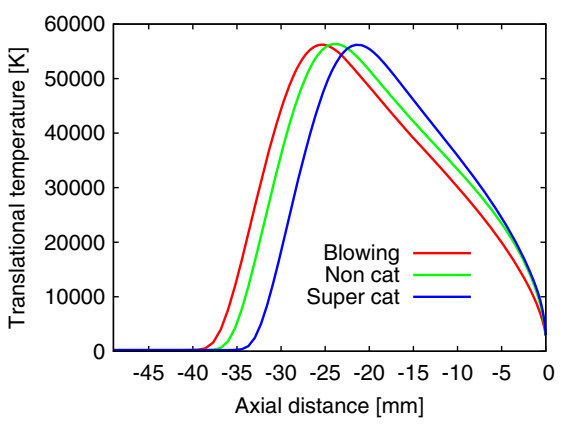

b) Reentry altitude of $76 \mathrm{~km}$

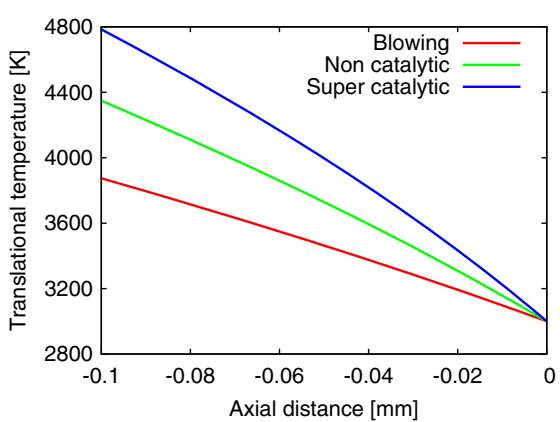

e) Reentry altitude of $76 \mathrm{~km}$ (near the wall)

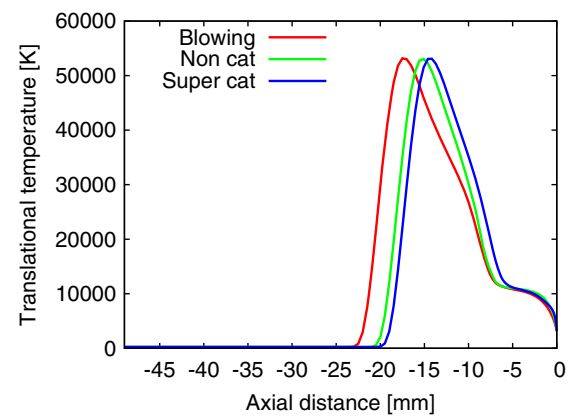

c) Reentry altitude of $68.9 \mathrm{~km}$

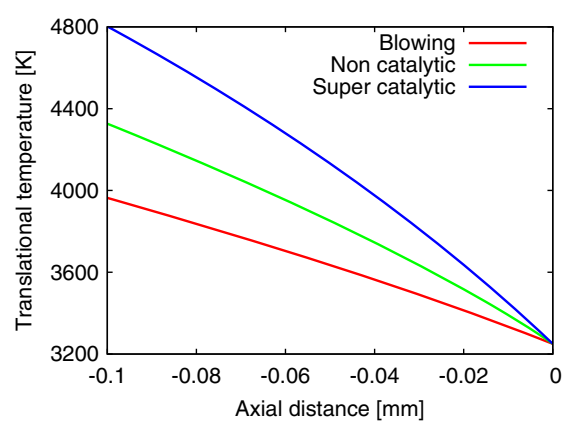

f) Reentry altitude of $68.9 \mathrm{~km}$ (near the wall)

Fig. 18 Blowing effects on stagnation line translational-rotational temperature.

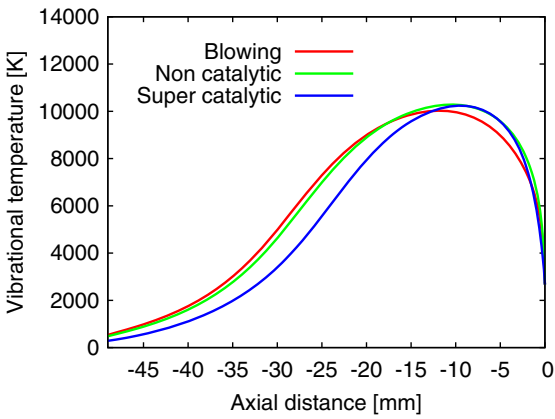

a) Reentry altitude of $81 \mathrm{~km}$

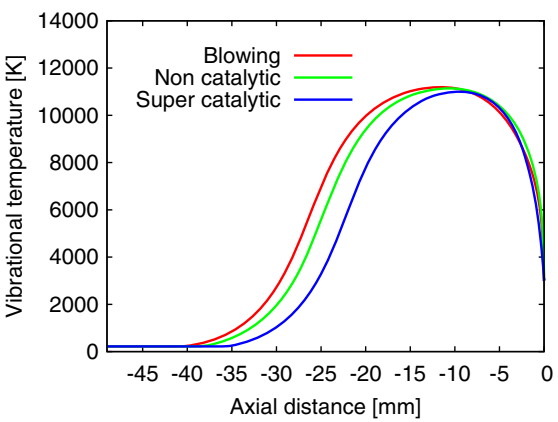

b) Reentry altitude of $76 \mathrm{~km}$

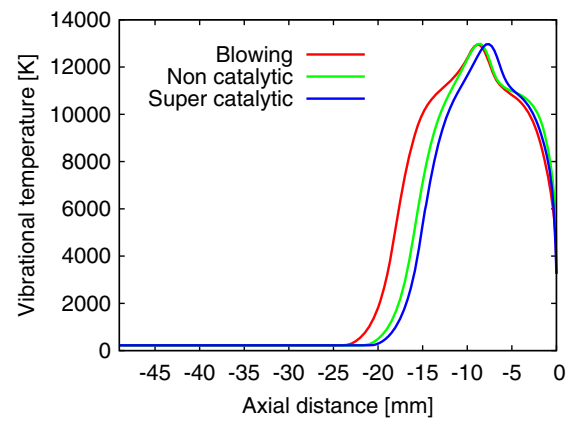

c) Reentry altitude of $68.9 \mathrm{~km}$

Fig. 19 Blowing reduction effects on stagnation line vibrational-electronic-electron temperature.

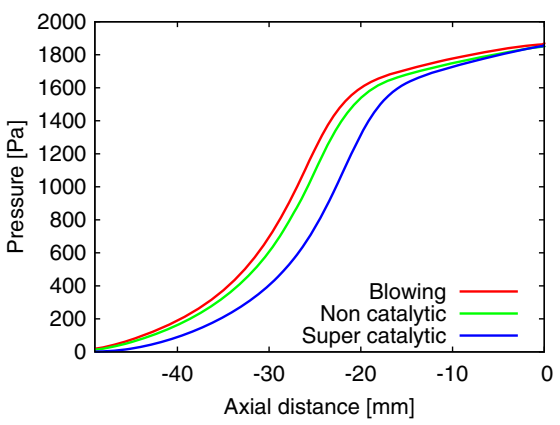

a) Reentry altitude of $81 \mathrm{~km}$

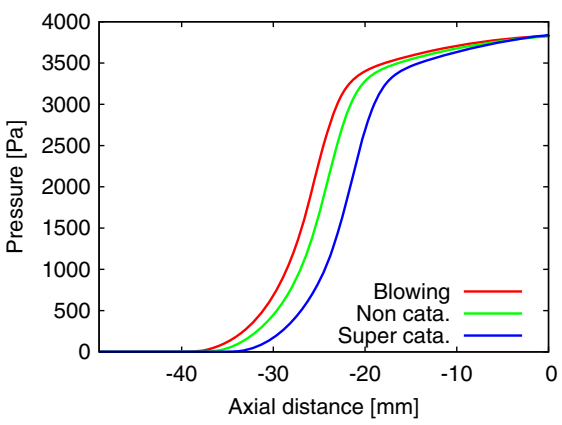

b) Reentry altitude of $76 \mathrm{~km}$

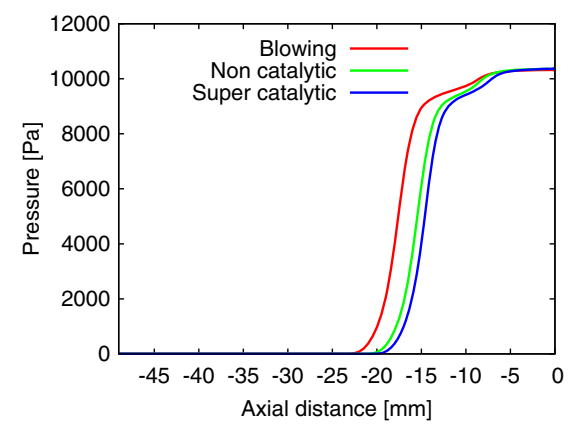

c) Reentry altitude of $68.9 \mathrm{~km}$

Fig. 20 Blowing effects on stagnation line pressure.

two orders of magnitude in a region where the vibrational-electronelectronic temperature is high. The same cannot be said about $\mathrm{CO}^{+}$ because nowhere in the flow is that molecule present in quantities that approach the concentration of $\mathrm{CO}$.

A comparison of the spectral emission from $\mathrm{CN}$ is presented in Fig. 23. To assess the importance of kinetic rates on radiation modeling, three different flow field simulations are used. The first one (labeled "Andersson") is considered the baseline and uses the
Table 3 Emission mechanisms considered for the radiative heat flux, excluding the air species

\begin{tabular}{ccc}
\hline \hline Species & Mechanism (electronic state transition) & Spectral range, $\mathrm{nm}$ \\
\hline $\mathrm{CN}$ & Violet $\left(B^{1} \Sigma-X^{1} \Sigma\right)$ & $230-462$ \\
$\mathrm{CO}$ & $4+\left(A^{1} \Pi-X^{1} \Sigma\right)$ & $110-385$ \\
$\mathrm{C}_{2}$ & Swan $\left(d^{3} \Pi-a^{4} \Pi\right)$ & $319-806$ \\
\hline \hline
\end{tabular}




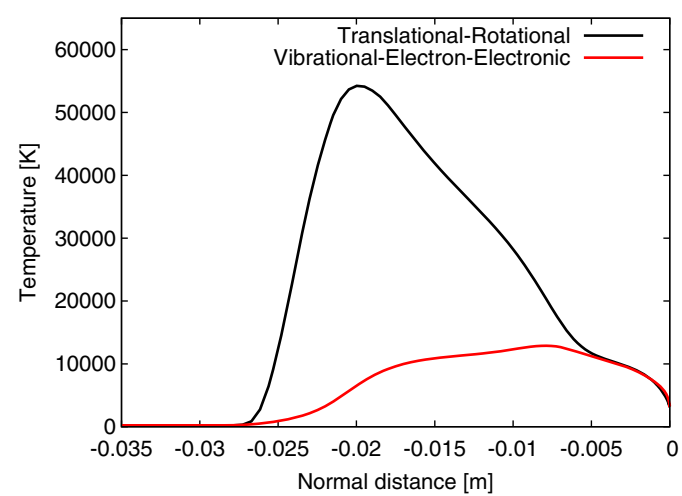

a) Temperatures $(r=0.00 \mathrm{~m})$

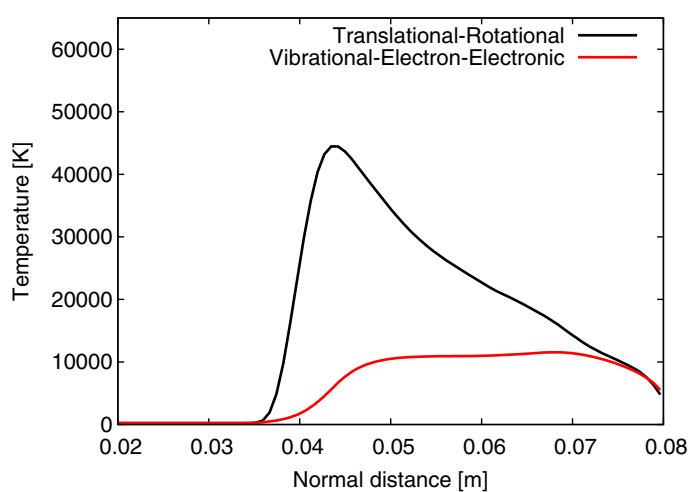

c) Temperatures $(r=0.20 \mathrm{~m})$

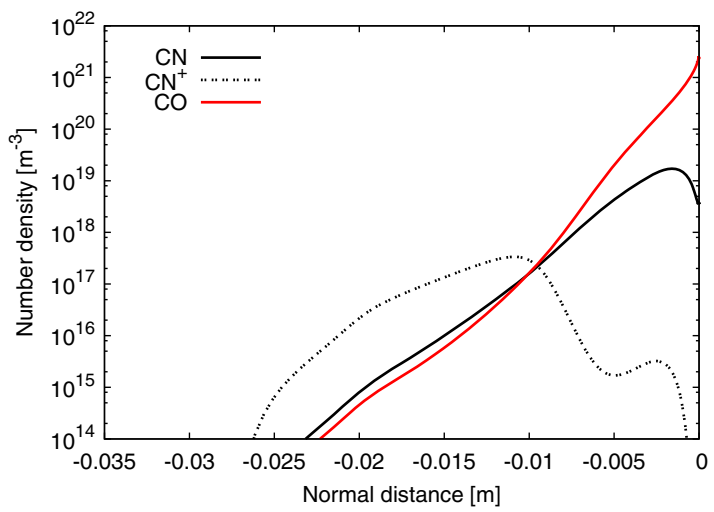

b) Radiating species from ablation $(r=0.0 \mathrm{~m})$

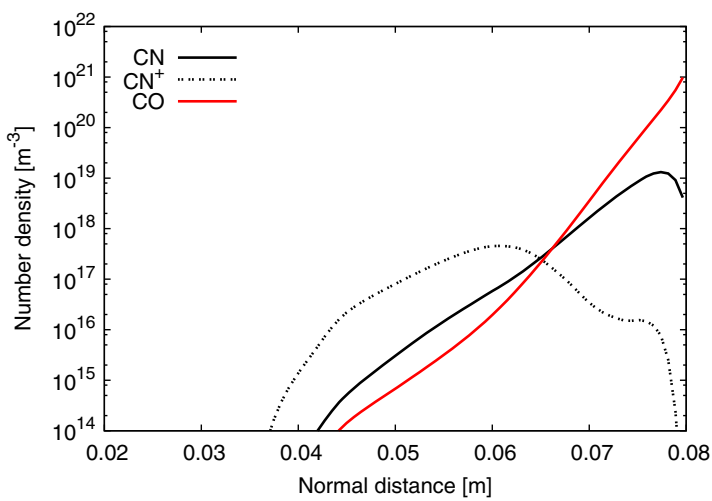

d) Radiating species from ablation $(r=0.20 \mathrm{~m})$

Fig. 21 Temperatures and radiating species concentrations along the first two of four parallel lines for the Stardust vehicle at $42 \mathrm{~s} \mathrm{into} \mathrm{reentry} \mathrm{(71} \mathrm{km).}$ Park's rate is used for the $\mathrm{CN} / \mathrm{CO}$ exchange reaction.

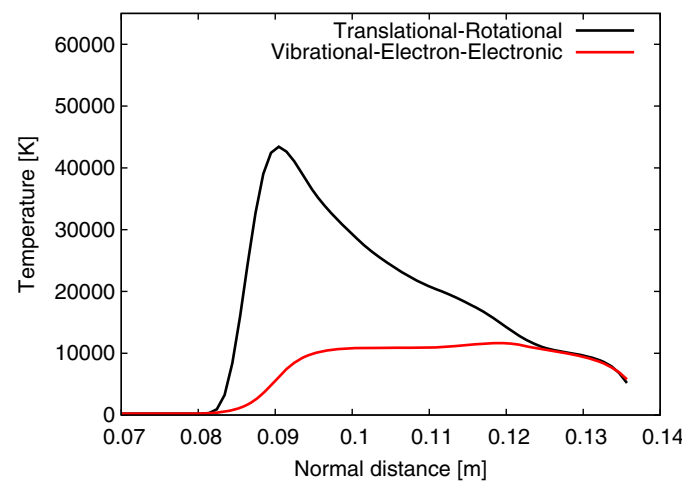

a) Temperatures $(r=0.30 \mathrm{~m})$

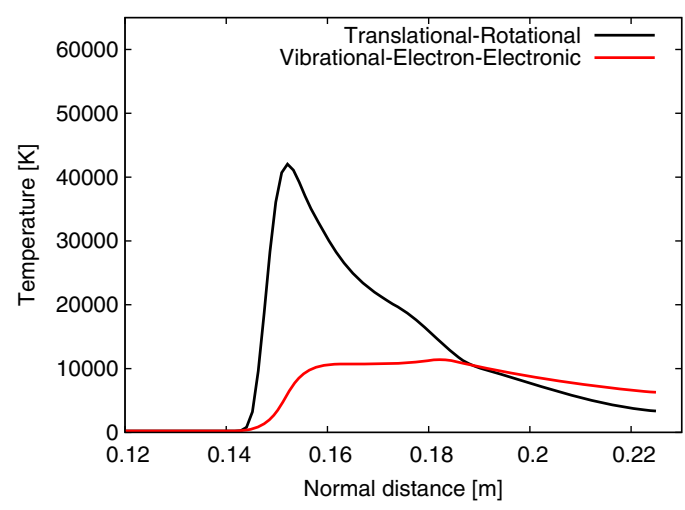

c) Temperatures $(r=0.42 \mathrm{~m})$

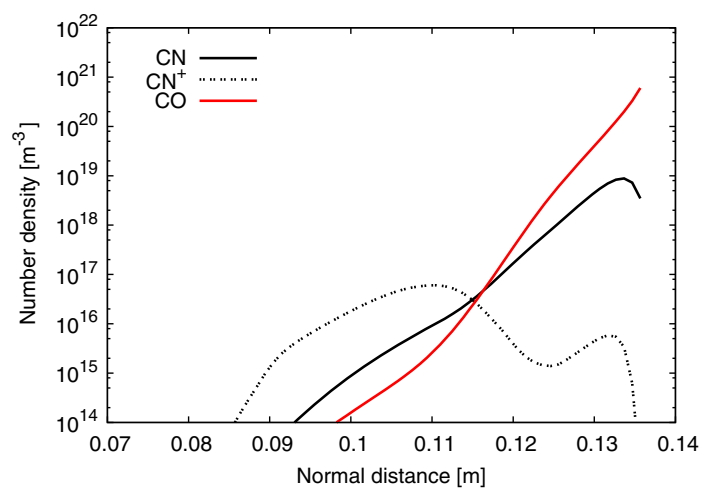

b) Radiating species from ablation $(r=0.30 \mathrm{~m})$

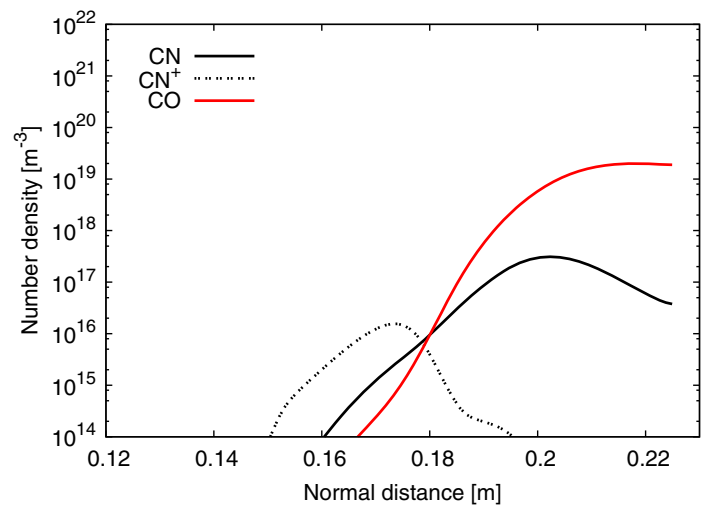

d) Radiating species from ablation $(r=0.42 \mathrm{~m})$

Fig. 22 Temperatures and radiating species concentrations along the last two of four parallel lines for the Stardust vehicle at $42 \mathrm{~s}$ into reentry (71 km). Park's rate is used for the $\mathrm{CN} / \mathrm{CO}$ exchange reaction. 


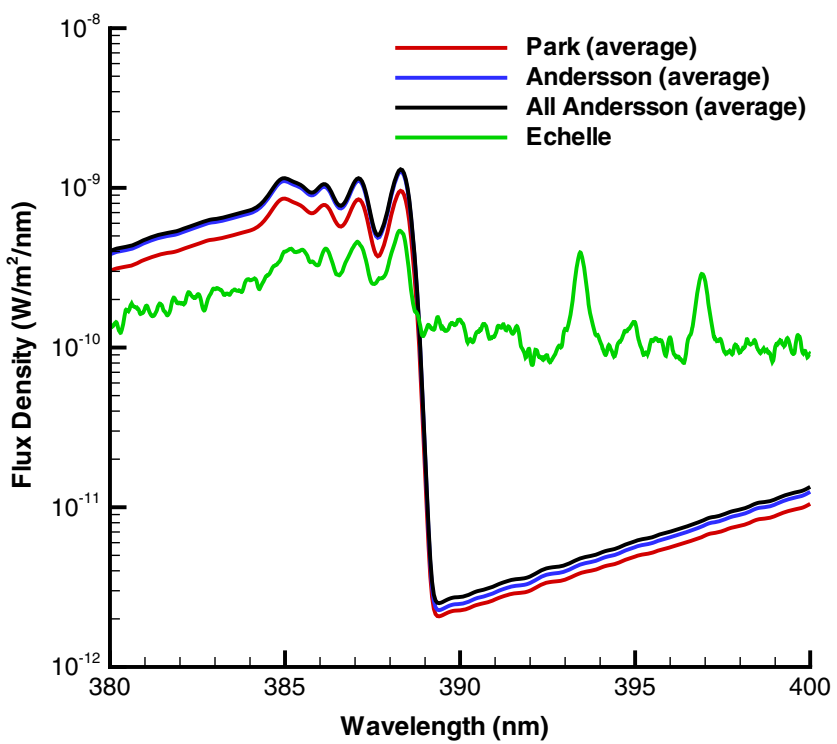

Fig. 23 Comparison of the $\mathrm{CN}$ spectral line for the Stardust reentry vehicle at $42 \mathrm{~s}(71 \mathrm{~km})$.

chemistry model detailed in Refs. $[12,14]$. The second one (labeled "Park") uses the the kinetic rates of Ref. [42] that were devised for Mars reentry and therefore tailored for high temperature. The last one, labeled "All Andersson" uses all of the kinetics rates of the $\mathrm{CN}$ / NO reduced model presented in Ref. [43].

It can be seen in that figure that the spectral computations match the echelle data remarkably well because the values are all within the same order of magnitude. Considering all the assumptions that are made throughout the modeling process and the uncertainties related to the conditions of the acquisition of the experimental data, an agreement such as this one exceeds expectations. The Park kinetic model appears to give better results than both of the Andersson models. However, all results are relatively close to the experimental data, and when one factors in all the assumptions that are made during the entire modeling process, no definitive recommendation can be made as to which rates to use. The interesting part, however, is that there are some noticeable differences in the predicted $\mathrm{CN}$ spectral intensity when the $\mathrm{CN} / \mathrm{CO}$ exchange reaction is modified.

Finally, the radiative heat flux was computed for the three cases. For all three sets of reaction rates, the total radiative flux is approximately $1 \%$ of the convective heat flux, making it negligible at this trajectory point. What is more important to acknowledge, however, is that a large portion (30-40\%) of the radiative heat flux is generated by
$\mathrm{CN}$ over the wavelength range of the echelle instrument (about 360 to $890 \mathrm{~nm}$ ).

As additional results, and in an attempt to validate the current methodology, the spectral line emissions for $\mathrm{CN}$ are compared to the experimental data obtained by the echelle instrument [41] at high altitude $(81 \mathrm{~km})$ and lower altitude $(71 \mathrm{~km})$. The radiative emission calculation is again performed along the stagnation line of a converged flow field solution using NEQAIR. The temperatures and species concentrations used as inputs NEQAIR are presented in Figs. 3 and 7, and the spectral emissions are presented in Fig. 24. As was previously reported, the lower-altitude trajectory point reasonably matches the experimental data because the discrepancy remains within one order of magnitude. As seen in [15], the difference would be even less if a spatially resolved input was used in NEQAIR instead of simply the stagnation line. The high-altitude trajectory point $(81 \mathrm{~km})$ gives an even better comparison. For those two results, the $\mathrm{CN}$ calculation was run independently of the air calculations.

\section{Conclusions}

To evaluate the mechanism of heat flux reduction caused by pyrolysis gas blowing, a comprehensive chemistry model for computing the flow around a reentry vehicle using an ablative heat shield has been used in a CFD code. The species used in the model have been selected with careful consideration of the flow physics, and the reactions have been evaluated and chosen from various sources in the literature. The model has been reduced to a more manageable number of species and reactions, using a zero-dimensional sensitivity analysis, and was validated using various experimental results.

The CFD software used to model the flow field is the hypersonic non-equilibrium code LeMANS, which was adequately modified to allow flow through the surface of the vehicle. As a test case, the Stardust reentry vehicle was used. This vehicle has been extensively studied in the past and is relatively simple to model. The first six trajectory points corresponding to the continuum regime were chosen because experimental data is available in the form of spectral radiative emission gathered by the echelle instrument [41].

As expected, the convective heat flux predicted using the carbonphenolic-in-air chemistry model was significantly reduced relative to the prediction obtained using a non-blowing air chemistry model. The species concentrations along the stagnation line were also presented, and it was shown that, at chemical equilibrium conditions, most species blown from the surface immediately react in the flow field and are transformed. These results clearly indicate the need to use an appropriate chemistry model in the flow field and that the chemistry model should be significantly different from that used to model pyrolysis gas behavior inside the TPS. Also, it was observed that the blowing rates were directly proportional to the mass diffusion

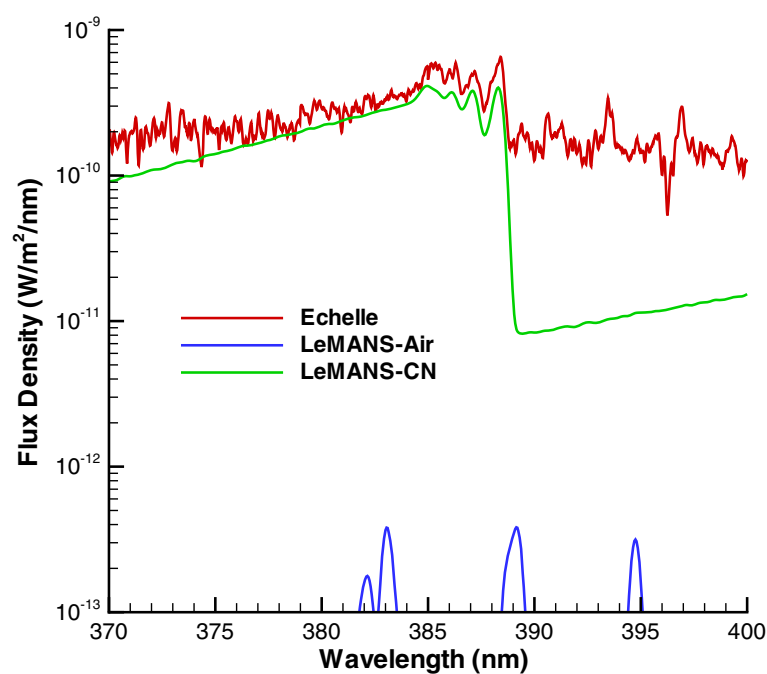

a) $81 \mathrm{~km}: 34 \mathrm{~s}$ into reentry

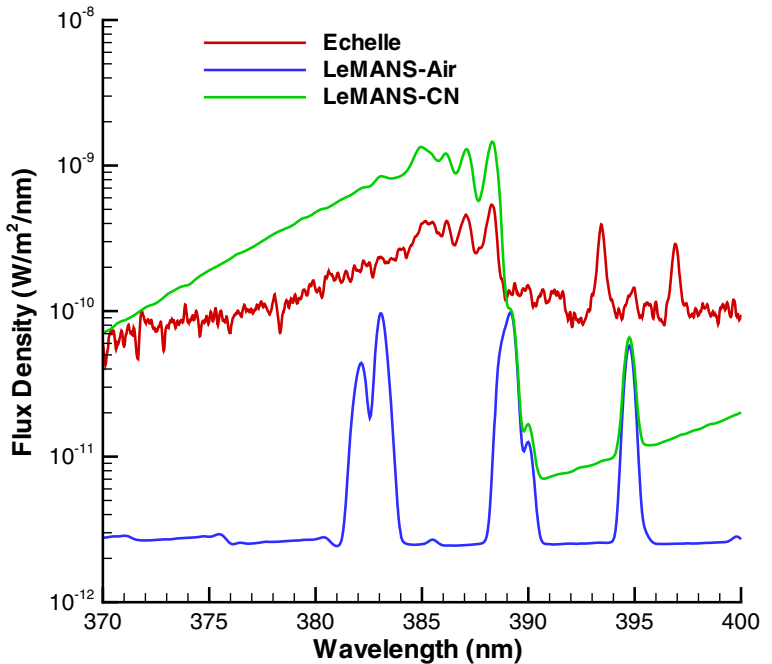

b) $71 \mathrm{~km}: 42 \mathrm{~s}$ into reentry

Fig. 24 Spectral emission for the Startdust reentry vehicle at 81 and $71 \mathrm{~km}$. 
heat flux, which in turn was directly proportional to the reduction of the translational-rotational conduction heat flux component. It was also noted that the main source of heat flux reduction for all trajectory points is the translational-rotational conduction component. This clearly indicates that the chemical composition of the boundary layer is of great importance and that the diffusion coefficients of each species, as well as the mixing rules, must be calculated with great care.

Finally, the flow field solution was used to perform analysis of the $\mathrm{CN}$ radiative spectral emission using NEQAIR. The result was compared to the experimental data obtained by the echelle instrument [41] at the 81 and $71 \mathrm{~km}$ trajectory points. The computed results were very close to the observed values, which provides increased confidence in the carbon-phenolic-in-air chemistry model and the overall approach.

\section{Acknowledgments}

Financial support for this work was provided in part by NASA Small Business Innovation Research Phase 2 award NNX10CC53P and NASA Experimental Program to Stimulate Competitive Research Research Area award NNX13AN04A. The authors would also like to thank Erin D. Farbar, from the University of Michigan, as well as Mike Wright, Ioana Cozmuta, David Hash, Nagi Mansour, Mike Barnhardt, Jean Lachaud, and Tahir Gökçen from NASA Ames Research Center for numerous insightful discussions.

\section{References}

-11] Suzuki, T., Sawada, K., Yamada, T., and Inatani, Y., "Experimental and Numerical Study of Pyrolysis Gas Pressure in Ablating Test Piece," Journal of Thermophysics and Heat Transfer, Vol. 19, No. 3, 2005, pp. $266-272$ doi: $10.2514 / 1.12211$

-[2] Dec, J. A., and Braun, R. D., "An Approximate Ablative Thermal Protection System Sizing Tool for Entry System Design," 44th AIAA Aerospace Sciences Meeting and Exhibit, AIAA Paper 2006-0780, Jan. 2006. doi: $10.2514 / 6.2006-780$

[3] Ayasoufi, A., Rahmani, R. K., Cheng, G., Koomullil, R., and Neroorkar, K., "Numerical Simulation of Ablation for Reentry Vehicles," 9th AIAA/ ASME Joint Thermophysics and Heat Transfer Conference, AIAA Paper 2006-2908, June 2006. doi: $10.2514 / 6.2006-2908$

- [4] Amar, A. J., Blackwell, B. F., and Edwards, J. R., "One-Dimensional Ablation Using a Full Newton's Method and Finite Control Volume Procedure," Journal of Thermophysics and Heat Transfer, Vol. 22, No. 1, 2008, pp. 71-82. doi: $10.2514 / 1.29610$

[5] Milos, F. S., and Chen, Y.-K., "Two-Dimensional Ablation, Thermal Response, and Sizing Program for Pyrolyzing Ablators," Journal of Spacecraft and Rockets, Vol. 46, No. 6, 2009, pp. 1089-1099. doi:10.2514/1.36575

[6] Venkatachari, B. S., Cheng, G. C., Koomullil, R. P., and Ayasoufi, A., "Computational Tools for Re-Entry Aerothermodynamics-Part 2. Surface Ablation," 46th AIAA Aerospace Sciences Meeting and Exhibit, AIAA Paper 2008-1218, Jan. 2008. doi:10.2514/6.2008-1218

- [7] Martin, A., and Boyd, I. D., "Simulation of Pyrolysis Gas Within a Thermal Protection System," 40th Thermophysics Conference, AIAA Paper 2008-3805, June 2008. doi: $10.2514 / 6.2008-3805$

[8] Park, C., Jaffe, R. L., and Partridge, H., "Chemical-Kinetic Parameters of Hyperbolic Earth Entry," Journal of Thermophysics and Heat Transfer, Vol. 15, No. 1, 2001, pp. 76-90. doi: $10.2514 / 2.6582$

[9] Suzuki, K., Kubota, H., Fujita, K., and Abe, T., "Chemical Nonequilibrium Ablation Analysis of MUSES-C Super-Orbital Reentry Capsule," 32nd Thermophysics Conference, AIAA Paper 1997-2481, 1997. doi:10.2514/6.1997-2481

[10] Olynick, D. R., Chen, Y.-K., and Tauber, M. E., "Aerothermodynamics of the Stardust Sample Return Capsule," Journal of Spacecraft and Rockets, Vol. 36, No. 3, 1999, pp. 442-462. doi: $10.2514 / 2.3466$
[11] Martin, A., Boyd, I. D., Cozmuta, I., and Wright, M. J., "Chemistry Model for Ablating Carbon-Phenolic Material During Atmospheric ReEntry," 48th AIAA Aerospace Sciences Meeting, AIAA Paper 20101175, Jan. 2010. doi:10.2514/6.2010-1175

[12] Martin, A., Boyd, I. D., Cozmuta, I., and Wright, M. J., "Kinetic Rates for Gas Phase Chemistry of Phenolic Based Carbon Ablator Decomposition in Atmospheric Air," Journal of Thermophysics and Heat Transfer, Vol. 29, No. 2, April 2015.

doi: $10.2514 / 1 . T 4184$

[13] Martin, A., and Boyd, I. D., "Assessment of Carbon-Phenolic-in-Air Chemistry Models for Atmospheric Re-Entry," 10th AIAA/ASME Joint Thermophysics and Heat Transfer Conference, AIAA Paper 20104656, June-July 2010. doi:10.2514/6.2010-5062

[14] Martin, A., and Boyd, I. D., "CFD Implementation of a Novel CarbonPhenolic-in-Air Chemistry Model for Atmospheric Re-Entry," 49th AIAA Aerospace Sciences Meeting, AIAA Paper 2011-0143, Jan. 2011. doi:10.2514/6.2011-143

[15] Martin, A., Farbar, E. D., and Boyd, I. D., "Numerical Modeling of the CN Spectral Emission of the Stardust Re-Entry Vehicle," 42nd AIAA Thermophysics Conference, AIAA Paper 2011-3125, June 2011. doi:10.2514/6.2011-3125

[16] Whiting, E. E., Park, C., Liu, Y., Arnold, J. O., and Paterson, J. A., "NEQAIR96, Non-equilibrium and Equilibrium Radiative Transport and Spectra Program: User's Manual," NASA RP-1389, Dec. 1996.

[17] Kee, R. J., Rupley, F. M., Miller, J. A., Coltrin, M. E., Grcar, J. F., Meeks, E., Moffat, H. K., Lutz, A. E., Dixon-Lewis, G., Smooke, M. D., Warnatz, J., Evans, G. H., Larson, R. S., Mitchell, R. E., Petzold, L. R., Reynolds, W. C., Caracotsios, M., Stewart, W. E., Glarborg, P., Wang, C., McLellan, C. L., Adigun, O., Houf, W., Chou, C. P., Miller, S. F., Ho, P., Young, P. D., Young, D. J., Hodgson, D. W., Petrova, M. V., and Puduppakkam, K. V., "CHEMKIN, Release 4.1.1," Reaction Design, San Diego, CA, 2007.

- [18] Martin, A., Scalabrin, L. C., and Boyd, I. D., "High Performance Modeling of an Atmospheric Re-Entry Vehicles," Journal of Physics: Conference Series, Vol. 341, No. 1, 2012, Paper 012002. doi:10.1088/1742-6596/341/1/012002

[19] Scalabrin, L. C., "Numerical Simulation of Weakly Ionized Hypersonic Flow Over Reentry Capsules," Ph.D. Thesis, University of Michigan, Ann Arbor, MI, 2007.

[20] Blottner, F. G., Johnson, M., and Ellis, M., "Chemically Reacting Viscous Flow Program for Multi-Component Gas Mixtures," Sandia National Lab., TR-SC-RR-70-754, Albuquerque, NM, 1971.

-[21] Wilke, C., "A Viscosity Equation for Gas Mixtures," Journal of Chemical Physics, Vol. 18, No. 4, 1950, pp. 517-519. doi:10.1063/1.1747673

[22] Vincenti, W. G., and Kruger, C. H., Introduction to Physical Gas Dynamics, Krieger, Malabar, FL, 1982, p. 12.

[23] Park, C., Non-Equilibrium Hypersonic Aerothermodynamics, WileyInterscience, New York, Feb. 1990, Paper 108111.

[24] Scalabrin, L. C., and Boyd, I. D., "Development of an Unstructured Navier-Stokes Solver for Hypersonic Non-Equilibrium Aerothermodynamics," 38th AIAA Thermophysics Conference, AIAA Paper 20055203, June 2005. doi: $10.2514 / 6.2005-5203$

[25] Scalabrin, L. C., and Boyd, I. D., "Numerical Simulation of Weakly Ionized Hypersonic Flow for Reentry Configurations," 9th AIAA/ASME Joint Thermophysics and Heat Transfer Conference, AIAA Paper 2006-3773, June 2006. doi:10.2514/6.2006-3773

[26] Alkandry, H., Boyd, I. D., Reed, E. M., Codoni, J. R., and McDaniel, J. C., "Interactions of Single-Nozzle Sonic Propulsive Deceleration Jets on Mars Entry Aeroshells," Journal of Spacecraft and Rockets, Vol. 48, No. 4, 2011, pp. 564-572. doi:10.2514/1.52232

[27] Alkandry, H., Boyd, I. D., Reed, E. M., Codoni, J. R., and McDaniel, J. C., "Aerodynamic Interactions of Reaction-Control-System Jets for Atmospheric Entry Aeroshells," AIAA Journal, Vol. 51, No. 5, 2013, pp. $1105-1118$. doi:10.2514/1.J051943

[28] McDaniel, J. C., Codoni, J. R., Reed, E. M., Alkandry, H., and Boyd, I. D., "Propulsion Deceleration Studies Using Planar Laser-Induced Iodine Fluorescence and Computational Fluid Dynamics," Journal of Spacecraft and Rockets, Vol. 50, No. 4, 2013, pp. 771-780. doi:10.2514/1.A32328

[29] Farbar, E. D., Boyd, I. D., and Martin, A., "Numerical Prediction of Hypersonic Flow Fields Including Effects of Electron Translational Non-equilibrium," Journal of Thermophysics and Heat Transfer, 
Vol. 27, No. 4, 2013, pp. 593-606. doi:10.2514/1.T3963

[30] Scalabrin, L. C., and Boyd, I. D., "Numerical Simulations of the FIRE-II Convective and Radiative Heating Rates," 39th AIAA Thermophysics Conference, AIAA Paper 2007-4044, June 2007. doi:10.2514/6.2007-4044

[31] Alkandry, H., Farbar, E., and Boyd, I., "Evaluation of Finite-Rate Surface Chemistry Models for Simulation of the Stardust Reentry Capsule," 43rd AIAA Thermophysics Conference, AIAA Paper 20122874, June 2012 doi: $10.2514 / 6.2012-2874$

[32] Alkandry, H., Boyd, I. D., and Martin, A., "Comparison of Models for Mixture Transport Properties for Flow Field Simulations of Ablative Heat-Shields," Journal of Thermophysics and Heat Transfer, Vol. 28, No. 4, Oct. 2014, pp. 569-582. doi: $10.2514 / 1 . \mathrm{T} 4233$

[33] Boyd, I. D., Martin, A., Wiebenga, J. E., and Jenniskens, P., "Hypersonic Flow and Radiation Analysis of the Automated Transfer Vehicle "Jules Verne"," Journal of Spacecraft and Rockets, Vol. 50, No. 1, 2013, pp. 124-136. doi:10.2514/1.A32208

[34] Wright, M. J., Candler, G. V., and Bose, D., "Data-Parallel Line Relaxation Method for the Navier-Stokes Equations," AIAA Journal, Vol. 36, No. 9, 1998, pp. 1603-1609. doi: $10.2514 / 2.586$

[35] Gnoffo, P. A., "Upwind-Biased, Point-implicit Relaxation Strategies for Viscous Hypersonic Flows," 9th Computational Fluid Dynamics Conference, AIAA Paper 1989-1972, 1989. doi:10.2514/6.1989-1972

[36] Martinelli, S., and Ruffin, S., "Validation Process for Blowing and Transpiration-Cooling in DPLR," 39th AIAA Thermophysics Conference, AIAA Paper 2007-4255, June 2007. doi: $10.2514 / 6.2007-4255$
[37] Thompson, R. A., and Gnoffo, P. A., "Implementation of a Blowing Boundary Condition in the LAURA Code," 46th AIAA Aerospace Sciences Meeting and Exhibit, AIAA Paper 2008-1243, Jan. 2008. doi: $10.2514 / 6.2008-1243$

[38] Martin, A., and Boyd, I. D., "Implicit Implementation of Material Response and Moving Meshes for Hypersonic Re-Entry Ablation," 47th AIAA Aerospace Sciences Meeting, AIAA Paper 2009-0670, Jan. 2009. doi: $10.2514 / 6.2009-670$

[39] Martin, A., and Boyd, I. D., "Strongly Coupled Computation of Material Response and Non-equilibrium Flow for Hypersonic Ablation," Journal of Spacecraft and Rockets, Vol. 52, No. 1, Jan. 2015. doi:10.2514/1.A32847

[40] Trumble, K. A., Cozmuta, I., Sepka, S., and Jenniskens, P., "Post-Flight Aerothermal Analysis of the Stardust Sample Return Capsule," 46th AIAA Aerospace Sciences Meeting and Exhibit, AIAA Paper 20081201, Jan. 2008. doi:10.2514/6.2008-1201

[41] Jenniskens, P., "Observations of the Stardust Sample Return Capsule Entry with a Slitless Echelle Spectrograph," Journal of Spacecraft and Rockets, Vol. 47, No. 5, 2010, pp. 718-735. doi: $10.2514 / 1.37518$

[42] Park, C., Howe, J. T., Jaffe, R. L., and Candler, G. V., "Review of Chemical Kinetic Problems of Future NASA Missions, 2: Mars Entries," Journal of Thermophysics and Heat Transfer, Vol. 8, No. 1, 1994, pp. 9-23. doi: $10.2514 / 3.496$

[43] Andersson, S., Markovic, N., and Nyman, G., "Computational Studies of the Kinetics of the $\mathrm{C}+\mathrm{NO}$ and $\mathrm{O}+\mathrm{CN}$ Reactions," Journal of Physical Chemistry A, Vol. 107, No. 28, 2003, pp. 5439-5447. doi: $10.1021 / \mathrm{jp} 0222604$ 
This article has been cited by:

1. Alexandre Martin, Huaibao Zhang, Kaveh A. Tagavi. 2017. An introduction to the derivation of surface balance equations without the excruciating pain. International Journal of Heat and Mass Transfer 115, 992-999. [Crossref]

2. Brett A. Cruden, Aaron M. Brandis, Christopher O. Johnston. Development of a Radiative Heating Margin Policy for Lunar Return Missions. Journal of Thermophysics and Heat Transfer, ahead of print1-13. [Abstract] [Full Text] [PDF] [PDF Plus]

3. Haoyue Weng, Alexandre Martin. Development of a Universal Solver and Its Application to Ablation Problems . [Citation] [PDF] [PDF Plus]

4. Brett A. Cruden, Aaron M. Brandis, Christopher O. Johnston. Development of a Radiative Heating Margin Policy for Lunar Return Missions . [Citation] [PDF] [PDF Plus]

5. Alexandre Martin, Sean C. C. Bailey, Francesco Panerai, Raghava S. C. Davuluri, Huaibao Zhang, Alexander R. Vazsonyi, Zachary S. Lippay, Nagi N. Mansour, Jennifer A. Inman, Brett F. Bathel, Scott C. Splinter, Paul M. Danehy. 2016. Numerical and experimental analysis of spallation phenomena. CEAS Space Journal 8:4, 229-236. [Crossref]

6. Stefan Loehle, Stefanos Fasoulas, Georg H. Herdrich, Tobias A. Hermann, Bartomeu Massuti-Ballester, Arne Meindl, Adam S. Pagan, Fabian Zander. The Plasma Wind Tunnels at the Institute of Space Systems: Current Status and Challenges . [Citation] [PDF] [PDF Plus]

7. Ali D. Omidy, Francesco Panerai, Jean R. Lachaud, Nagi N. Mansour, Alexandre Martin. 2016. Effects of Water Phase Change on the Material Response of Low-Density Carbon-Phenolic Ablators. Journal of Thermophysics and Heat Transfer 30:2, 473-478. [Citation] [Full Text] [PDF] [PDF Plus]

8. Raghava Davuluri, Huaibao Zhang, Alexandre Martin. Effect of spalled particles thermal degradation on a hypersonic flow field environment . [Citation] [PDF] [PDF Plus] 